NATIONAL LABORATORY

MANAGED BY UT-BATTELLE

FOR THE DEPARTMENT OF ENERGY

\title{
Summary of Large Concrete Samples
}

June 2013

Prepared by

Dwight Clayton

Cyrus Smith

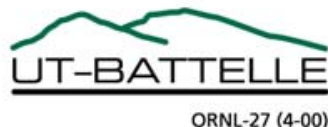




DOCUMENT AVAILABILITY
Reports produced after January 1, 1996, are generally available free via the U.S. Department of
Energy (DOE) Information Bridge.
Web site http://www.osti.gov/bridge
Reports produced before January 1, 1996, may be purchased by members of the public from the
following source.
National Technical Information Service
5285 Port Royal Road
Springfield, VA 22161
Telephone 703-605-6000 (1-800-553-6847)
TDD 703-487-4639
Fax 703-605-6900
E-mail info@ntis.gov
Web site http://www.ntis.gov/support/ordernowabout.htm
Reports are available to DOE employees, DOE contractors, Energy Technology Data Exchange
(ETDE) representatives, and International Nuclear Information System (INIS) representatives from
the following source.
Office of Scientific and Technical Information
P.O. Box 62
Oak Ridge, TN 37831
Telephone 865-576-8401
Fax 865-576-5728
E-mail reports@osti.gov
Web site http://www.osti.gov/contact.html

This report was prepared as an account of work sponsored by an agency of the United States Government. Neither the United States Government nor any agency thereof, nor any of their employees, makes any warranty, express or implied, or assumes any legal liability or responsibility for the accuracy, completeness, or usefulness of any information, apparatus, product, or process disclosed, or represents that its use would not infringe privately owned rights. Reference herein to any specific commercial product, process, or service by trade name, trademark, manufacturer, or otherwise, does not necessarily constitute or imply its endorsement, recommendation, or favoring by the United States Government or any agency thereof. The views and opinions of authors expressed herein do not necessarily state or reflect those of the United States Government or any agency thereof. 


\title{
SUMMARY OF LARGE CONCRETE SAMPLES
}

\author{
Dwight Clayton \\ Cyrus Smith
}

Date Published: June 2013

Prepared by

OAK RIDGE NATIONAL LABORATORY

Oak Ridge, Tennessee 37831-6283

managed by

UT-BATTELLE, LLC

for the

U.S. DEPARTMENT OF ENERGY

under contract DE-AC05-00OR22725 



\section{CONTENTS}

Page

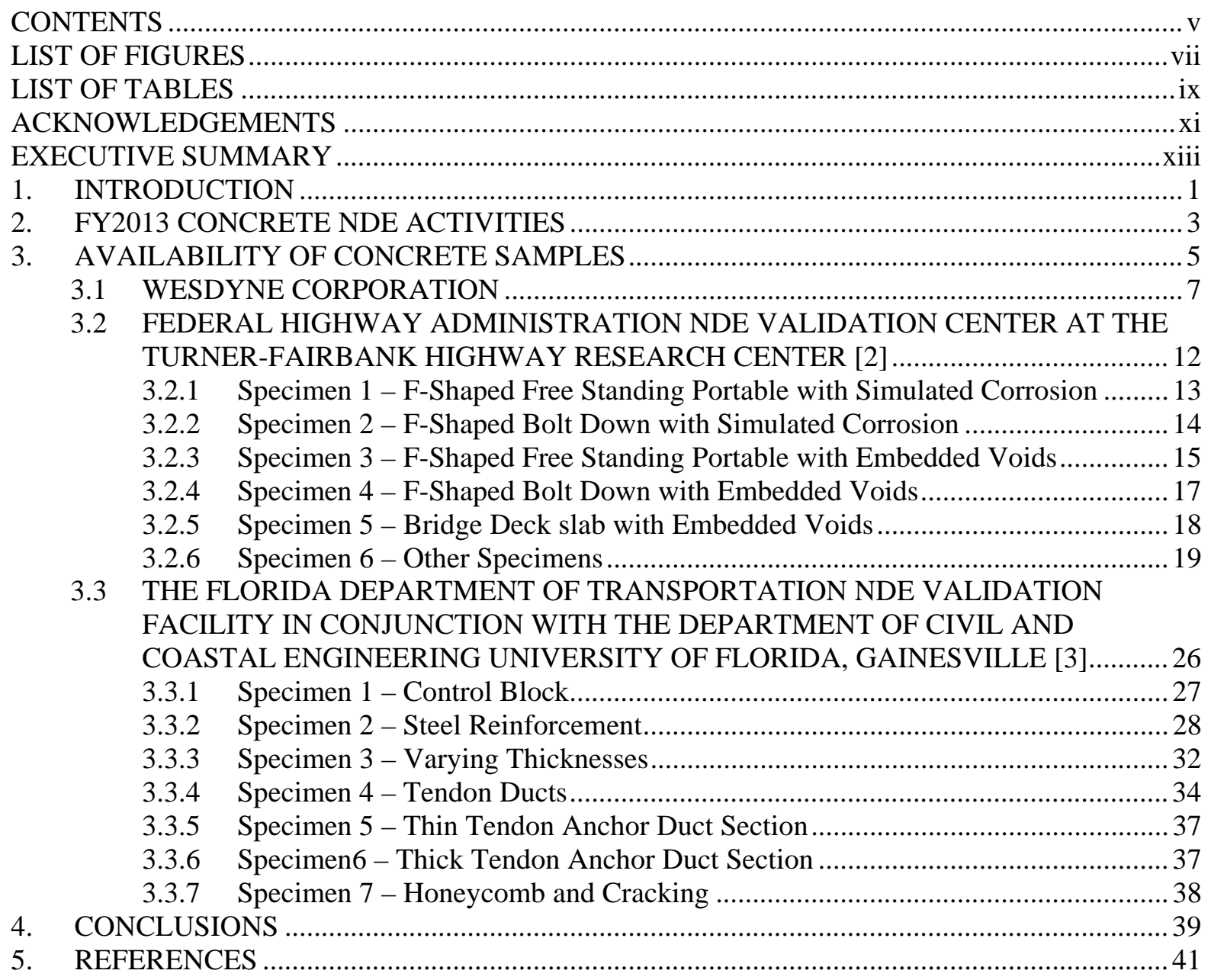





\section{LIST OF FIGURES}

Figure Page

Figure 1. The workshop participants identified six key R\&D projects. ............................... 3

Figure 2. Planned RY13 concrete NDE activities result in four milestones.......................... 3

Figure 3. Typical nuclear power plant containment structure. ........................................... 6

Figure 4. Westinghouse AP1000 Shield Building Drawing. ............................................. 7

Figure 5. WesDyne 3X3X10 Samples showing void simulators....................................... 8

Figure 6. WesDyne concrete specimen after all concrete poured....................................... 9

Figure 7. WesDyne Westinghouse AP1000 Shield Building NDE Evaluation Section......... 10

Figure 8. NDE Evaluations being performed on AP1000 Shield Building Section............... 11

Figure 9. F-shaped free standing portable barrier. ........................................................ 13

Figure 10. Different levels of simulated corroded........................................................ 14

Figure 11. F-shaped bolt-down barrier with different levels of simulated. .......................... 14

Figure 12. Different levels of simulated corroded U-shaped rebar. .................................. 15

Figure 13. F-shaped bolt-down barrier fabrication with simulated corrosion. ...................... 15

Figure 14. F-shaped free standing portable barrier with simulated voids............................ 16

Figure 15. F-shaped free standing portable barrier fabrication......................................... 16

Figure 16. F-shaped bolt-down barrier with different levels of simulated voids................... 17

Figure 17. F-shaped bolt-down barrier fabrication with embedded simulated flaws. ........... 17

Figure 18. Embedded flaws in the mock up bridge deck slab. ......................................... 18

Figure 19. Schematic of mock up bridge deck with attached concrete barrier..................... 19

Figure 20. Concrete barrier anchored to mockup bridge deck slab. ................................... 19

Figure 21. Barrier specimen with various steel reinforcement........................................ 20

Figure 22. Use of ground-penetrating radar on barrier concrete specimen. ......................... 21

Figure 23. Ground-penetrating radar instrument output. ................................................. 21

Figure 24. Use of phased array ultrasonic equipment on barrier concrete specimen............ 22

Figure 25. Phased array ultrasonic instrument output. ................................................. 22

Figure 26. Bridge support specimen at FHWA NDE Validation Center.............................. 23

Figure 27. Bridge support specimen undergoing steel reinforcement corrosion testing. ....... 24

Figure 28. Bridge deck specimens. .............................................................................. 25

Figure 29. Extensively reinforced high performance concrete specimens. .......................... 25

Figure 30 Form used for all standard blocks ............................................................ 27

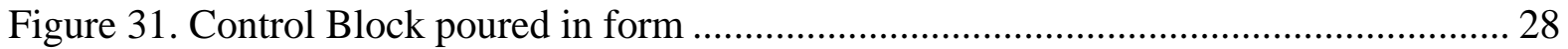

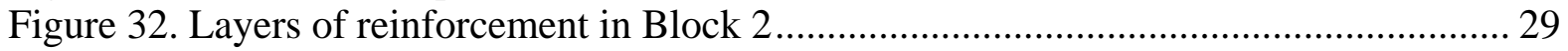

Figure 33. Steel reinforcement layers on the upper side of Block 2 .................................. 30

Figure 34. Steel reinforcement layers on the lower side of Block 2 ................................. 31

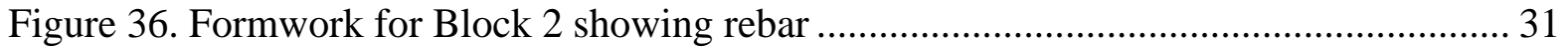

Figure 35. Consolidation of Bock 2 concrete .............................................................. 31

Figure 37. Top and sectional view of Block 3 ............................................................ 33

Figure 38. Four tendon ducts of two different diameters in Specimen 4 ............................. 34

Figure 39. Preparing ducts to be partially grouted........................................................ 35

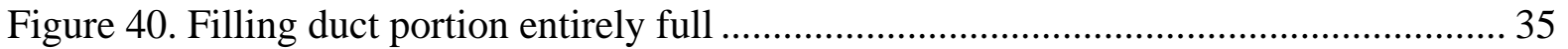

Figure 41. Fully filled duct sections curing ................................................................. 35

Figure 42. Ducts placed in framework.......................................................................... 36

Figure 43. Pouring and compacting concrete .............................................................. 36

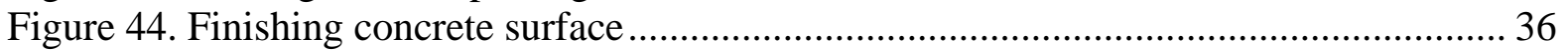

Figure 45. Specimen 5 showing thickness, anchor point, and tendons and ducts ................. 37 
Figure 46. Specimen 6 showing thickness, anchor point, and tendons and ducts ................ 37

Figure 47. Honeycomb and crack areas of Specimen 7 ................................................ 38 


\section{LIST OF TABLES}

Table

Table 1. FHWA NDE Validation Center Specimens....................................................... 13

Table 2. Corrosion simulation for each barrier section for Specimens 1 and 2................... 13

Table 3. Defect simulation for each barrier section for Specimens 3 and 4...................... 16

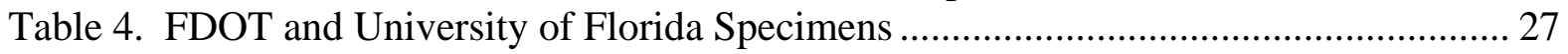

Table 5. Thicknesses and locations in Block 3 ............................................................... 32 



\section{ACKNOWLEDGEMENTS}

The authors would like to express our appreciation to our colleagues; Jack Lareau at WesDyne Corporation, Dr. Shane Boone at the Federal Highway Administration NDE Validation Center at the Turner-Fairbank Highway Research Center, the Florida Department of Transportation NDE Validation Facility and Dr. Chris Ferraro and Jordan Nelson at the Department of Civil and Coastal Engineering, University of Florida - Gainesville. 



\section{EXECUTIVE SUMMARY}

Materials issues are a key concern for the existing nuclear reactor fleet as material degradation can lead to increased maintenance, increased downtime, and increased risk. Extending reactor life to 60 years and beyond will likely increase susceptibility and severity of known forms of degradation. Additionally, new mechanisms of materials degradation are also possible. The purpose of the U.S. Department of Energy Office of Nuclear Energy's Light Water Reactor Sustainability (LWRS) Program is to develop technologies and other solutions that can improve the reliability, sustain the safety, and extend the operating lifetimes of nuclear power plants beyond 60 years.

The intent of this LWRS Concrete nondestructive evaluation (NDE) roadmap is to define Research \& Development (R\&D) actions to address gaps between available NDE concrete techniques and the technology needed to make quantitative measurements to determine the durability and performance of concrete structures on our current nuclear power plant (NPP) fleet.

A multitude of concrete-based structures are typically part of a light water reactor (LWR) plant to provide foundation, support, shielding, and containment functions. Concrete has been used in the construction of NPPs because of three primary properties: its inexpensiveness, its structural strength, and its ability to shield radiation. Examples of concrete structures important to the safety of LWR plants include containment building, spent fuel pool, and cooling towers. This use has made its long-term performance crucial for the safe operation of commercial NPPs.

With respect to the concrete structures, age-related degradation may affect engineering properties, structural resistance/capacity, failure mode, and location of failure initiation that in turn may affect the ability of a structure to withstand challenges in service. In order to ensure the safe operation of NPPs, it is essential that the effects of potential degradation of the plant structures, as well as systems and components, be assessed and managed during both the current operating license period as well as subsequent license renewal periods. In contrast to many mechanical and electrical components, replacement of many concrete structures is impractical. Therefore it is necessary that safety issues related to plant aging and continued service of the concrete structures are resolved through sound scientific and engineering understanding.

Unlike most metallic materials, reinforced concrete is a non-homogeneous material, a composite with low density matrix, a mixture of cement, sand, aggregate and water, and a high density reinforcement (typically 5\% in NPP containment structures), made up of steel rebar or tendons. Plants have been typically built with local cement and aggregate fulfilling the design specification regarding strength, workability, and durability, but as a consequence, each plant's concrete composition is unique and complex. In addition, NPPs concrete structures are often inaccessible, containing large volumes and massively thick concrete structures that are exposed to different environments (moisture, temperature) and a diversity of degradation mechanisms (high temperatures, radiation exposure, chemical reactions) at different plant sites, all of which adds to the complexity of determining the integrity/quality of the concrete.

The ORNL Concrete NDE efforts are directed toward addressing gaps between available techniques and the technology needed to make these measurements on our current NPP fleet. Several important themes are the focus of our work: 
1) Need to survey available samples

Comparative testing on the various NDE concrete measurement techniques will require concrete samples with known material properties, voids, internal microstructure flaws and reinforcement locations. These samples can be artificially created under laboratory conditions where the various properties can be controlled. In addition, concrete samples that have been removed from the field and exposed to known degradation mechanisms (different levels of radiation / temperature / chemical reaction) provide the most realistic concrete aging specimens.

2) Technique(s) to perform volumetric imaging on thick reinforced concrete sections A technique or a combination of techniques that could reliably and quickly generate an image of the volume of thick concrete structures will significantly enhance the interpretability of the outcome of the various NDE measurement methodologies and is greatly desired.

3) Determine physical and chemical properties as a function of depth Knowledge of the physical and chemical properties of a concrete structure, especially as a function of depth, will provide highly relevant information on its structural integrity.

4) Techniques to examine interfaces between concrete and other materials In some cases, the structural concrete to be inspected is covered by a steel liner. Presently there are no techniques designed for inspecting concrete through steel.

5) Development of acceptance criteria - model and validation Through modeling and validation, an acceptance criterion needs to be developed to determine that a concrete structure is "good enough." For each NDE concrete measurement metric (void size, crack size, reinforcement degradation, physical properties), an upper and lower acceptance boundary needs to be determined.

6) Need for automated scanning system for any of the NDE concrete measurement systems Due to the massively large concrete areas to be surveyed, an automated scanning system for any NDE concrete measurements is greatly desired.

This report is focused on the ORNL efforts toward item \#1 above: Need to survey available samples. Three organizations were identified who possessed concrete test samples which may be applicable to evaluating, developing, and testing NDE techniques for thick, heavily reinforced concrete as is found in nuclear power plants: (1) WesDyne Corporation, (2) Federal Highway Administration NDE Validation Center at the Turner-Fairbank Highway Research Center, and (3) the Florida Department of Transportation NDE Validation Facility in conjunction with the Department of Civil and Coastal Engineering, University of Florida - Gainesville. ORNL staff visited each of these organizations to identify and evaluate the concrete sample which were available for NDE research. This report documents these available samples and the ORNL evaluation of them.

The WesDyne Corporation has two large concrete samples from their NDE evaluation of the Westinghouse AP1000 Shield Building: (1) a 3' x 3" x 10" specimen with simulated voids at known locations and (2) a 30' x 30' x 3' specimen which is an actual upper section of an AP1000 Shield Building again with simulated voids at known locations. While these specimens are representative of an AP1000 Shield Building, they are not representative of older reactor containment buildings because of radically different design and construction methods. Additionally, these specimens, as will be the case with all large concrete samples, are very heavy and must essentially be used for NDE research at their current location which is at WesDyne’s Watts’ Mill Service Center in Pittsburg, Pennsylvania. 
The Federal Highway Administration NDE Validation Center at the Turner-Fairbank Highway Research Center is mainly concerned with validating commercial NDE techniques for use on bridges and roadways. Typical bridge and roadway construction has thinner cross sections of concrete and less steel reinforcement than nuclear power plants. However, the Turner-Fairbank Research Center has several NDE research concrete specimens with an assortment of embedded flaws. These specimens typically take the shape of an F-shaped concrete roadway barrier (Jersey Barrier). However, they also have actual bridge and roadway segments which could be used for NDE research. These specimens are located in McLean, Virginia and are available for NDE research.

The Florida Department of Transportation NDE Validation Facility is similar to the Federal Highway Administration NDE Validation Center at the Turner-Fairbank Highway Research Center, but is state sponsored instead of federally sponsored. However, the magnitude of the NDE funding appears to be very similar between the two with, at this time, the state center being more involved in evolving concrete NDE techniques than the federal center. This is probably due to the association between Florida DOT and the University of Florida and the requirement of the federal facility to respond to the needs of the states. The FDOT NDE Validation Center also has an assortment of specimens which can be used for NDE research. These specimens are typically slabs with an assortment of flaws and steel reinforcement to study commonly occurring construction techniques and flaws using various NDE techniques.

For the studies planned for this project, adequate test blocks/specimens play a key role, since they can provide defined conditions under which the different NDE concrete measurement methods can be evaluated. Material properties as well as the location of reinforcement, tendon ducts, and test flaws must be well documented.

Artificial test blocks allow the isolation of certain testing problems as well as the variation of certain parameters. Because of the controlled conditions in the laboratory, the number of unknown variables can be decreased, which makes it possible to focus on specific aspects, investigate them in detail, and gain further information on the capabilities and limitations of the methods. However, the materials used for the fabrication of the artificial test blocks may not be representative of the original concrete fabricated some 40 to 50 years ago: old cements being usually coarser than present-day cement. Fine cements set and hydrate, generating a high heat release at the early age that can cause thermal cracking and potentially delayed ettringite formation if not cured correctly. The original admixture (plasticizer, etc.) may not be available anymore.

To minimize artifacts caused by boundary effects, the dimensions of the specimens should not be too compact. The exact size will depend on the NDE method used. The minimum dimensions of the test sample are directly related to the thickness of the sample. The first reflected wave received is normally assumed to be from the rear surface. If the ultrasonic wave is modeled as a spherical propagation from the point source then the distance from the source location to the rear surface must be the minimum dimension.

The concrete sample specimens at the Federal Highway Administration NDE Validation Center at the Turner-Fairbank Highway Research Center, and the Florida Department of Transportation NDE Validation Facility in conjunction with the Department of Civil and Coastal Engineering Department University of Florida, Gainesville are usable for concrete NDE evaluations, however, none of them, especially the specially constructed ones detailed in this report, are of the cross sectional thickness or have the amount of steel reinforcing which is typical of a commercial nuclear power plant structures.

The High Flux Isotope Reactor (HFIR) is located at ORNL and possesses thick, heavily reinforced concrete structure although they are not as extensive as those of commercial nuclear power plants. The concrete in these HFIR structures has also been irradiated which would make them more typical of some 
concrete structures at commercial nuclear power plants. Some of these concrete structures at HFIR could be made available for NDE research. Additionally, there are several commercial nuclear power plants undergoing the decommissioning process and it would be ideal to secure concrete sections of these plants for use in testing NDE techniques. However, the cost for obtaining, transportation, and storage of these samples is high. To obtain samples large enough to eliminate boundary effects in NDE evaluations, their weigh would be prohibitive for most methods of shipping (3' x 9' x 9' section is about the largest which could be shipped using typical trucks over highways).

It is the recommendation of this report that at least one concrete test sample representative of the cross section of a commercial nuclear power reactor be fabricated for concrete NDE evaluations. Additionally, the HFIR reactor should be utilized for concrete NDE research and evaluation and an effort should be make to obtain or have access to concrete specimens from decommissioned commercial nuclear power plants. 


\section{INTRODUCTION}

A multitude of concrete-based structures are typically part of a light water reactor (LWR) plant to provide foundation, support, shielding, and containment functions. Concrete has been used in the construction of nuclear power plants (NPPs) because of three primary properties-its inexpensiveness, its structural strength, and its ability to shield radiation. Examples of concrete structures important to the safety of LWR plants include the containment building, spent fuel pool, and cooling towers. This use has made its long-term performance crucial for the safe operation of commercial NPPs.

Extending reactor life to 60 years and beyond will likely increase susceptibility and severity of known forms of degradation. Additionally, new mechanisms of materials degradation are also possible. Unlike most metallic materials, reinforced concrete is a nonhomogeneous material, a composite with low-density matrix, a mixture of cement, sand, aggregate and water, and a high-density reinforcement (typically 5\% in nuclear power plant containment structures), made up of steel rebar or tendons. Plants have been typically built with local cement and aggregate fulfilling the design specification regarding strength, workability, and durability; as a consequence, each plant's concrete composition is unique and complex. In addition, NPP concrete structures are often inaccessible and contain large volumes of massively thick concrete. These structures are exposed to different environments (moisture, temperature) and a diversity of degradation mechanisms (high temperatures, radiation exposure, and chemical reactions) at different plant sites, all of which adds to the complexity of determining the integrity/quality of the concrete.

With respect to the concrete structures in NPPs, age-related degradation may affect engineering properties, structural resistance/capacity, failure mode, and locations of failure initiation that in turn may affect the ability of a structure to withstand challenges in service. In contrast to many mechanical and electrical components, replacement of many concrete structures is currently considered impractical. Therefore, it is necessary that safety issues related to plant aging and concrete structures are resolved through sound scientific and engineering understanding.

To assist in the identification and evaluation of the needed Research \& Development (R\&D), a Light Water Reactor Sustainability (LWRS) Concrete Nondestructive Evaluation (NDE) workshop was held at Oak Ridge National Laboratory (ORNL) on July 31, 2012 to address gaps between available NDE concrete techniques and the technology needed to make quantitative measurements to determine the durability and performance of concrete structures in our current NPP fleet. Expert participants were identified from a variety of disciplines as well as an assortment of institutions. The represented institutions include the Electrical Power Research Institute (EPRI), the US Nuclear Regulatory Commission (NRC), Electricité de France, universities, industry, the Swiss Association for Technical Inspection, and Department of Energy (DOE) National Laboratories.

While the workshop participants identified many potential and worthwhile R\&D projects related to concrete NDE, six key technology gaps were identified as being the highest priority. [1]

1) Need to survey available samples

Comparative testing on the various NDE concrete measurement techniques will require concrete samples with known material properties, voids, internal microstructure flaws and reinforcement locations. These samples can be artificially created under laboratory conditions where the various properties can be controlled. In addition, concrete samples that have been removed from the field and exposed to known degradation mechanisms (different levels of radiation / temperature /chemical reaction) provide the most realistic concrete aging specimens. 
2) Technique(s) to perform volumetric imaging on thick reinforced concrete sections A technique or a combination of techniques that could reliably and quickly generate an image of the volume of thick concrete structures will significantly enhance the interpretability of the outcome of the various NDE measurement methodologies and is greatly desired.

3) Determine physical and chemical properties as a function of depth

Knowledge of the physical and chemical properties of a concrete structure, especially as a function of depth, will provide highly relevant information on its structural integrity.

4) Techniques to examine interfaces between concrete and other materials In some cases, the structural concrete to be inspected is covered by a steel liner. Presently there are no techniques designed for inspecting concrete through steel.

5) Development of acceptance criteria - model and validation Through modeling and validation, an acceptance criterion needs to be developed to determine that a concrete structure is "good enough.” For each NDE concrete measurement metric (void size, crack size, reinforcement degradation, physical properties), an upper and lower acceptance boundary needs to be determined.

6) Need for automated scanning system for any of the NDE concrete measurement systems Due to the massively large concrete areas to be surveyed, an automated scanning system for any NDE concrete measurements is greatly desired.

These six key R\&D projects were further prioritized and arranged based on the maturity of the technology required to resolve the gap, the expected impact/importance, and likelihood of completing the projects within a time frame that could make a difference. Availability of resources (funding and resources) was not used as a consideration for determining relative priority. 


\section{FY2013 CONCRETE NDE ACTIVITIES}

As shown in Figure 1, two projects were selected as the highest priority with proposed starts in FY2013 a) Survey of Available Samples, and b) Volumetric Imaging of Thick Sections. While the proposed schedule in Figure 2 assumed slightly over \$1M in FY2013 for these two tasks, significantly less funding is actually available. Therefore the original tasks associated with these projects have been re-

scoped/manipulated, i.e. some tasks were shifted to later years, to accommodate current funding levels while still making progress toward the goals identified by the workshop participants. Specifically, the volumetric imaging of thick sections was limited in scope to just investigating ultrasonic methods in FY2013. The planned R\&D activities for FY2013 are illustrated in Figure 2.

\begin{tabular}{|c|c|c|c|c|c|c|c|c|c|c|c|c|c|c|c|c|c|c|c|c|c|c|c|c|c|c|}
\hline \multirow{2}{*}{ 10 } & \multirow{2}{*}{ Task Name } & \multirow{2}{*}{ Stort } & \multirow{2}{*}{ Finish } & 2012 & \multicolumn{3}{|c|}{2013} & \multicolumn{4}{|c|}{2014} & \multicolumn{4}{|c|}{2015} & \multicolumn{4}{|c|}{2016} & \multicolumn{4}{|c|}{2017} & \multicolumn{3}{|c|}{2018} \\
\hline & & & & as & $a_{1}$ & $\alpha_{2}$ & \begin{tabular}{l|l}
$a 3$ & $a_{4}$ \\
\end{tabular} & $a 1$ & \begin{tabular}{|l|l|}
$a 2$ & \\
\end{tabular} & os & $a 4$ & $a^{-1}$ & $a_{2}$ & as & $a^{4}$ & as & $a_{2}$ & \begin{tabular}{|l|l} 
as \\
\end{tabular} & as & $a 1$ & $a_{2}$ & $a_{3}$ & as & $a t$ & $Q 2$ & $a_{3}$ \\
\hline 1 & Survey Available Samples & $10 / 1 / 2012$ & 9/30/2013 & & & & $\mathbf{a}$ & & & & & & & & & & & & & & & & & & & \\
\hline 2 & Volumetric Imaging of Thick Sections & $10 / 1 / 2012$ & $9 / 30 / 2016$ & & & & & & & & & & & & & & & & & & & & & & & \\
\hline 3 & Physical \& Chemical Properties & $10 / 1 / 2014$ & $9 / 28 / 2018$ & & & & & & & & & & & & & & & & & & & & & & & \\
\hline 4 & $\begin{array}{l}\text { Interfaces between Concrete and Other } \\
\text { Materials }\end{array}$ & $10 / 1 / 2013$ & 9/30/2016 & & & & 2 & & & & & & & & & & & & & & & & & & & \\
\hline 5 & Acceptance Criteria Development & $10 / 1 / 2013$ & 9/29/2016 & & & & $\boldsymbol{E}$ & & & & & & & & & & & $\mathbf{A}$ & $\boldsymbol{\Delta}$ & & & & & & & \\
\hline 6 & Automated Scanning System & 10/3/2016 & 9/28/2018 & & & & & & & & & & & & & & & & & & & & & & & \\
\hline
\end{tabular}

Figure 1. The workshop participants identified six key R\&D projects.

\begin{tabular}{|c|c|c|c|c|c|c|c|c|c|c|c|c|c|c|c|c|}
\hline \multirow{2}{*}{10} & \multirow{2}{*}{ Task Name } & \multirow{2}{*}{ Start } & \multirow{2}{*}{ Finish } & \multirow{2}{*}{ Duration } & \multicolumn{3}{|c|}{2012} & \multicolumn{9}{|c|}{2013} \\
\hline & & & & & oct & Nov & Dec & san & Feb & Mor & Apr & May & sun & sul & Aug & Sep \\
\hline 1 & LWRS Concrete NDE FY13 Activities & $10 / 1 / 2012$ & 9/30/2013 & 261d & & & & & & & & & & & & \\
\hline 2 & $\begin{array}{l}\text { Coordinate with EPRI and NRC to } \\
\text { ensure complementary R\&D }\end{array}$ & $10 / 1 / 2012$ & 9/30/2013 & 261d & & & & & & & & & & & & \\
\hline 3 & $\begin{array}{l}\text { Meet with EPRI to discuss Concrete } \\
\text { NDE }\end{array}$ & $10 / 23 / 2012$ & $10 / 24 / 2012$ & $2 d$ & I & & & & & & & & & & & \\
\hline 4 & $\begin{array}{l}\text { Letter Report Summarizing the } \\
\text { Complementary R\&D }\end{array}$ & $12 / 21 / 2012$ & $12 / 21 / 2012$ & Od & & & 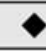 & & & & & & & & & \\
\hline 5 & $\begin{array}{l}\text { Obtain detailed understanding of } \\
\text { recent concrete issues }\end{array}$ & $10 / 1 / 2012$ & $3 / 1 / 2013$ & $110 \mathrm{~d}$ & & & & & & & & & & & & \\
\hline 6 & $\begin{array}{l}\text { Letter Report on Recent Concrete } \\
\text { Issues at NPPs }\end{array}$ & $3 / 1 / 2013$ & $3 / 1 / 2013$ & od & & & & & 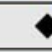 & 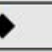 & & & & & & \\
\hline 7 & $\begin{array}{l}\text { Identify Availability of Concrete NDE } \\
\text { Samples and any gaps }\end{array}$ & $1 / 1 / 2013$ & $6 / 28 / 2013$ & $129 \mathrm{~d}$ & & & & & & & & & & & & \\
\hline 8 & $\begin{array}{l}\text { Letter Report Summarizing Available } \\
\text { Concrete Samples }\end{array}$ & $6 / 28 / 2013$ & $6 / 28 / 2013$ & Od & & & & & & & & & 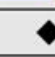 & & & \\
\hline 9 & $\begin{array}{l}\text { Evaluate existing ultrasonic concrete } \\
\text { NDE technique }\end{array}$ & $12 / 17 / 2012$ & $9 / 30 / 2013$ & 206d & & & & & & & & & & & & \\
\hline 10 & $\begin{array}{l}\text { Investigate electronic } \\
\text { improvements }\end{array}$ & $12 / 17 / 2012$ & $7 / 31 / 2013$ & $163 d$ & & & & & & & & & & & & \\
\hline 11 & $\begin{array}{l}\text { SPIE Smart Structures and NDE } \\
\text { Conference }\end{array}$ & $3 / 11 / 2013$ & $3 / 14 / 2013$ & $4 d$ & & & & & & I & & & & & & \\
\hline 12 & $\begin{array}{l}\text { Investigate signal processing } \\
\text { enhancements }\end{array}$ & $5 / 31 / 2013$ & 9/30/2013 & $87 \mathrm{~d}$ & & & & & & & & & & & & \\
\hline 13 & $\begin{array}{l}\text { Quantitative Nondestructive } \\
\text { Evaluation Conference }\end{array}$ & $7 / 15 / 2013$ & $7 / 19 / 2013$ & $5 d$ & & & & & & & & & & I & & \\
\hline 14 & $\begin{array}{l}\text { ORNL Technical Report on Results } \\
\text { of Ultrasonic Technique }\end{array}$ & 9/27/2013 & $9 / 27 / 2013$ & Od & & & & & & & & & & & & \\
\hline
\end{tabular}

Figure 2. Planned RY13 concrete NDE activities result in four milestones.

This ORNL Technical Memorandum represents the deliverable associated with ID \#8 "Letter Report Summarizing Available Concrete Samples”. 



\section{AVAILABILITY OF CONCRETE SAMPLES}

The concrete structures in nuclear power plants are thick in cross section and heavily reinforced with steel. Figure 3 illustrates a typical nuclear power plant concrete and steel reinforced containment structure which has the following specifications:

- Wall Thickness: $3-4$ feet

- Dome Thickness: 3 feet

- Floor Thickness: If there are rock anchors (2 feet), if not 10 feet

- Inside Diameter: 150 feet

- Liner Thickness: $1 / 4$ to $3 / 8$ inch

- Height: 150 to 200 feet

- Volume: $2.5 \times 10^{6}$ cubic feet

- Liner Material: Carbon Steel

- Containment shape: vertical right cylinder with hemispherical or shallow dome

- Concrete Cover over Bottom Liner: 2 to 3 feet

- Reinforcing Material: Mild Steel

o \# 18 bars (2.257 inch diameter, 4.00 in $^{2}$ cross sectional area)

o \# 8 bars (1.000 inch diameter, 0.79 in $^{2}$ cross sectional area)

In this typical plant, the upper reinforced concrete containment is typically three and a half feet thick with two layers of \#18 steel reinforcing bars on 12 inch centers vertically and horizontally on each face at a distance of 6 inches from each face of a containment structure ranging from 150 to 200 feet tall with a diameter of approximately 150 feet. The lower cylindrical walls of the containment are even larger in order to carry the entire dead load, including the upper containment, to the base slab. The walls are at least four feet thick with \#18 vertical bars at 12 inches spacing for each face and \#18 horizontal bars on both sides of the vertical reinforcing; the ties are made of \#8 bars.

Other than power plants, there are not many applications where critical concrete structures are this thick and reinforced. Therefore, there are not many industries other than the nuclear power plant or power plant industry who are interested in performing NDE on thick and reinforced concrete structures. This leads to the lack of readily available samples of thick and heavily reinforced concrete for performing NDE evaluations, research and training. 

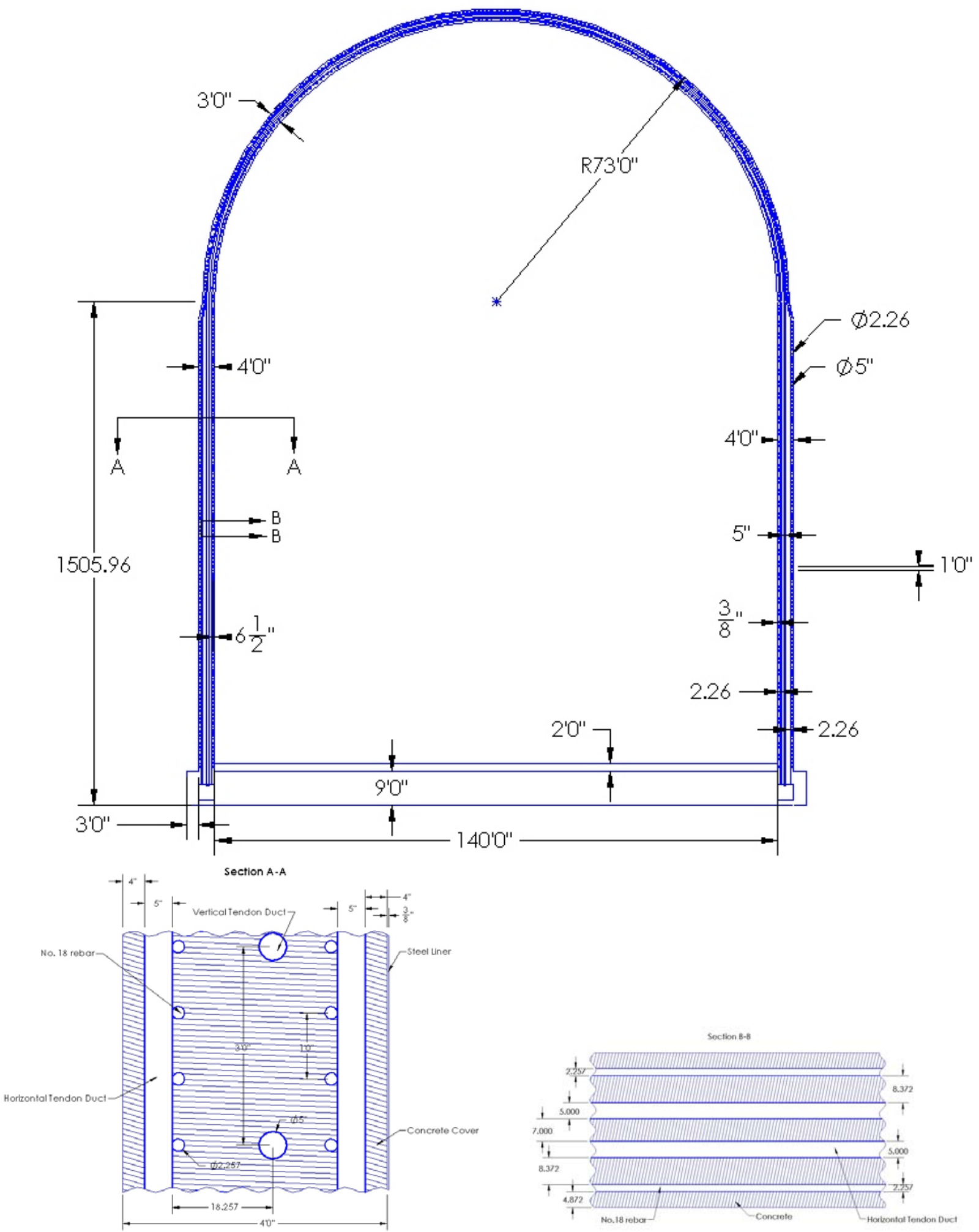

Figure 3. Typical nuclear power plant containment structure. 
The industry which typically performs the most NDE on concrete structures is the bridge and roadway industry. While bridge and roadway structures are thinner and less reinforced, they have a good base of NDE research to support their field NDE programs to detect, identify, and repair concrete failures.

To determine what concrete samples are available in the United States which are applicable to the concrete NDE evaluations of nuclear power plants, ORNL utilized their extensive body of contacts which were established through the LWRS Concrete NDE Workshop conducted last August. Three organizations responded that they possessed such samples; the WestDyne Corporation, the Federal Highway Administration NDE Validation Center at the Turner-Fairbank Highway Research Center, and the Florida Department of Transportation NDE Validation Facility in conjunction with the Department of Civil and Coastal Engineering Department University of Florida, Gainesville.

\subsection{WESDYNE CORPORATION}

Wesdyne Corporation is a subsidiary of the Westinghouse Corporation. They are involved with Westinghouse in certifying the AP1000 containment which is a non-traditional, sectional, steel and concrete containment structure shown in Figure 4.

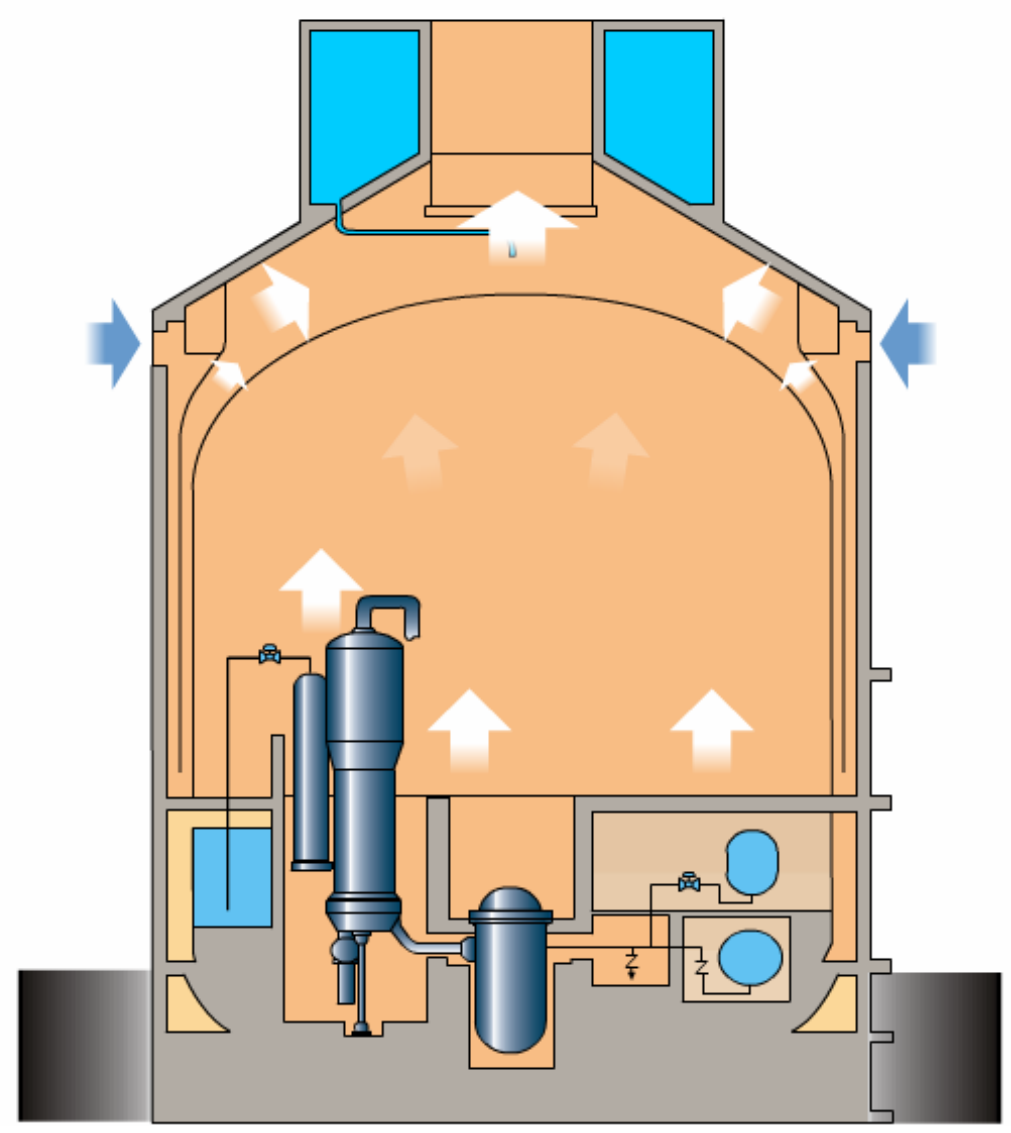

Figure 4. Westinghouse AP1000 Shield Building Drawing.

The Westinghouse Shield Building is constructed of 30 foot by 30 foot sections of pre-assembled steel forms. These steel forms have 1 inch thick steel inner and outer walls which are separated by 3 feet of space which will be filled with concrete. The inner and outer steel walls are connected by steel struts and 
there are partial length concrete anchors attached to both the inner and outer steel walls. These preassembled steel forms are welded together forming the shield building and then concrete is continuously poured into the three foot space to provide rigidity, shielding, and impact (airplane) protection.

Initially, WesDyne fabricated a 3 foot wide by 3 foot deep by 10 foot long concrete specimen to use for NDE evaluations. This specimen is shown in Figures 5 and 6. The 1 inch thick inner and outer steel walls along with the steel cross struts and partial length concrete anchors can be seen in Figure 5. Figure 6 illustrates the specimen after all the concrete was poured.

WesDyne evaluated the ultrasonic and impulse-echo NDE techniques using this sample and found that the physical dimensions were limiting for the testing being performed. Therefore, the decision to fabricate a full 30 foot by 30 foot Shield Building section was made.

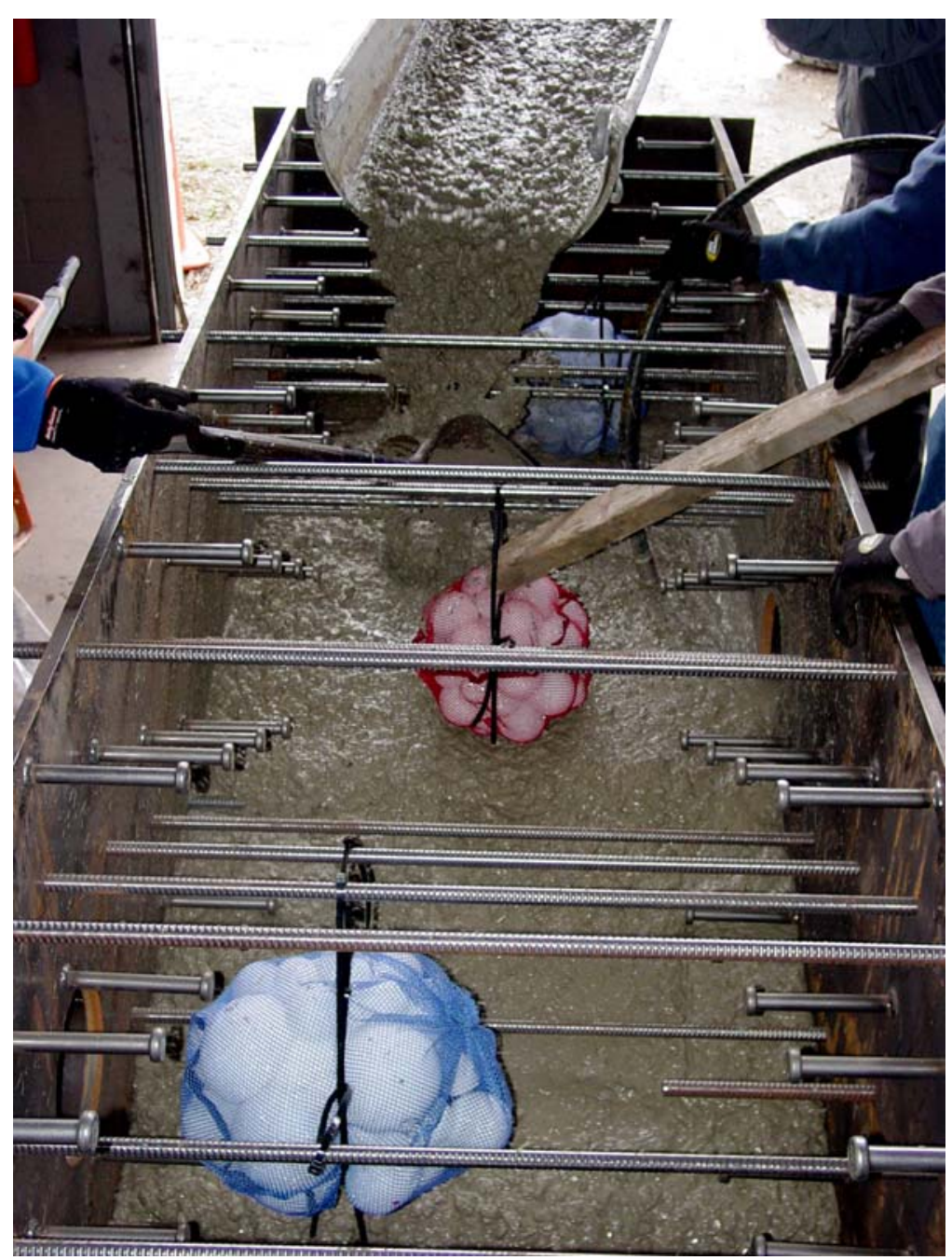

Figure 5. WesDyne 3X3X10 Samples showing void simulators. 


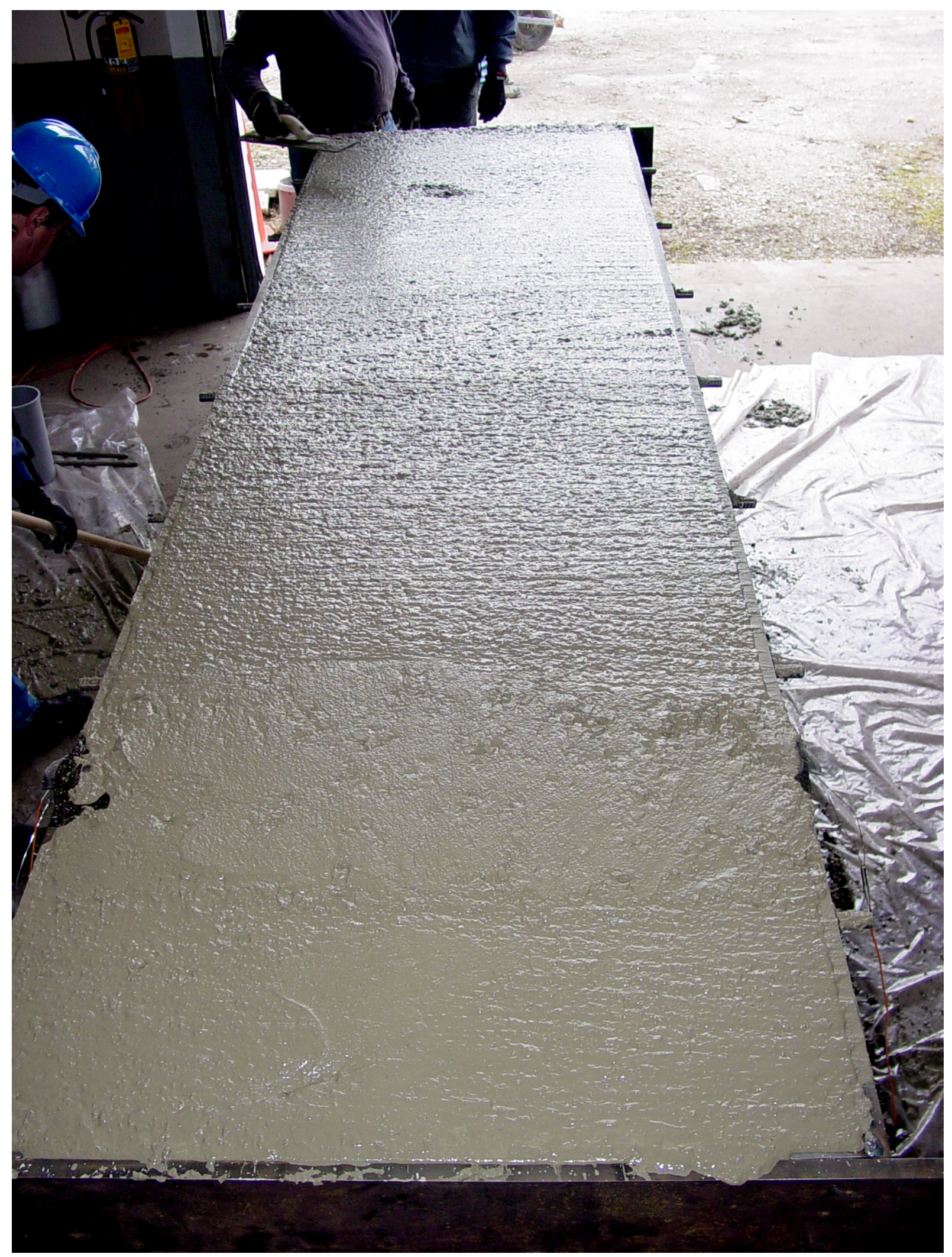

Figure 6. WesDyne concrete specimen after all concrete poured. 
The WesDyne single 30 foot by 30 foot shield building section for NDE evaluations is shown in Figures 7 and 8. Shrinkage of the poured concrete away from the inner and outer steel walls during curing of the concrete is of concern because any air gap will prohibit NDE inspection of the concrete from the external steel faces of the walls. In this section, WesDyne again tied plastic mesh bags containing foam balls to a limited number of specific steel cross struts before the concrete was poured to simulate voids within the concrete.

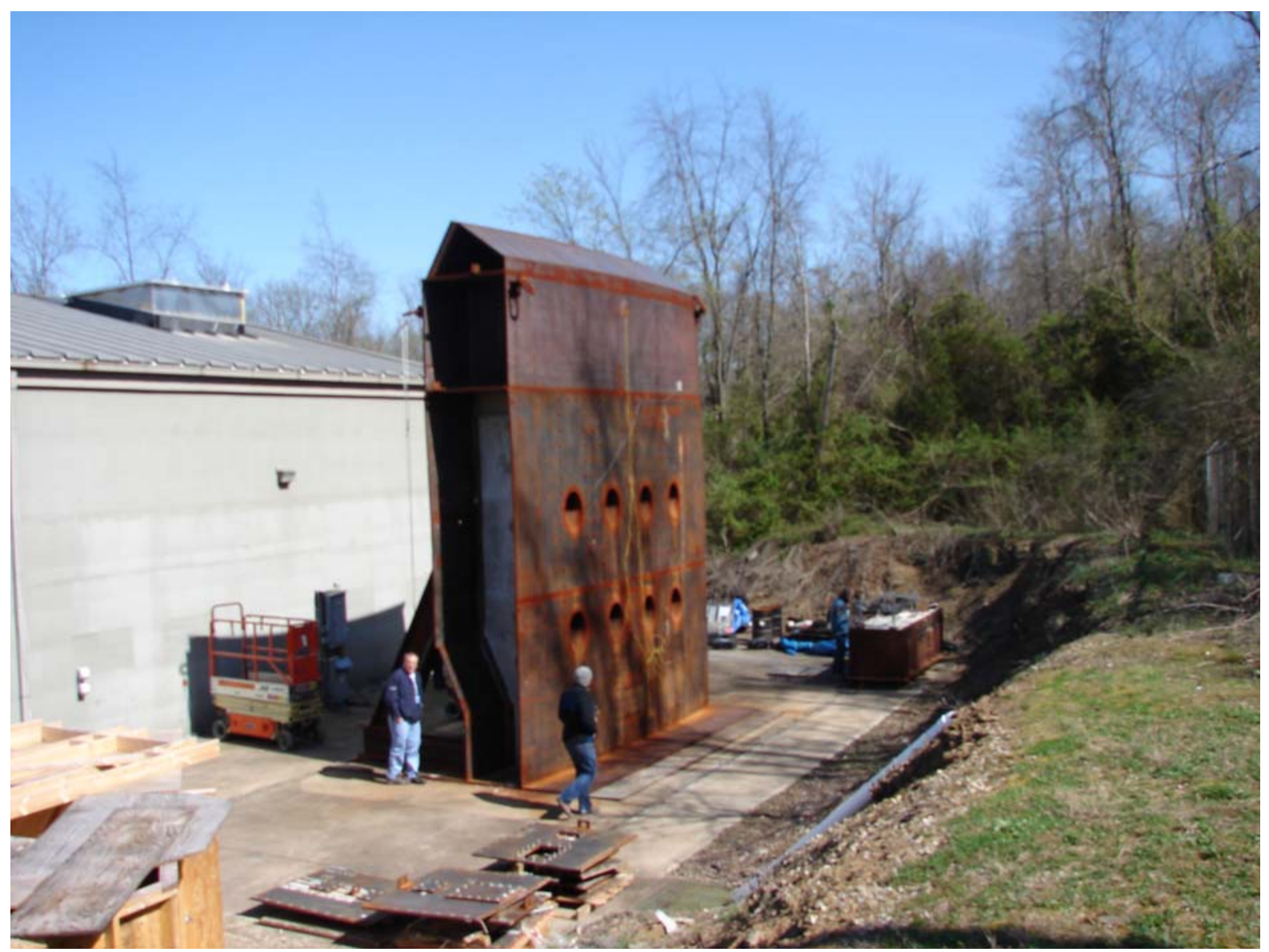

Figure 7. WesDyne Westinghouse AP1000 Shield Building NDE Evaluation Section. 


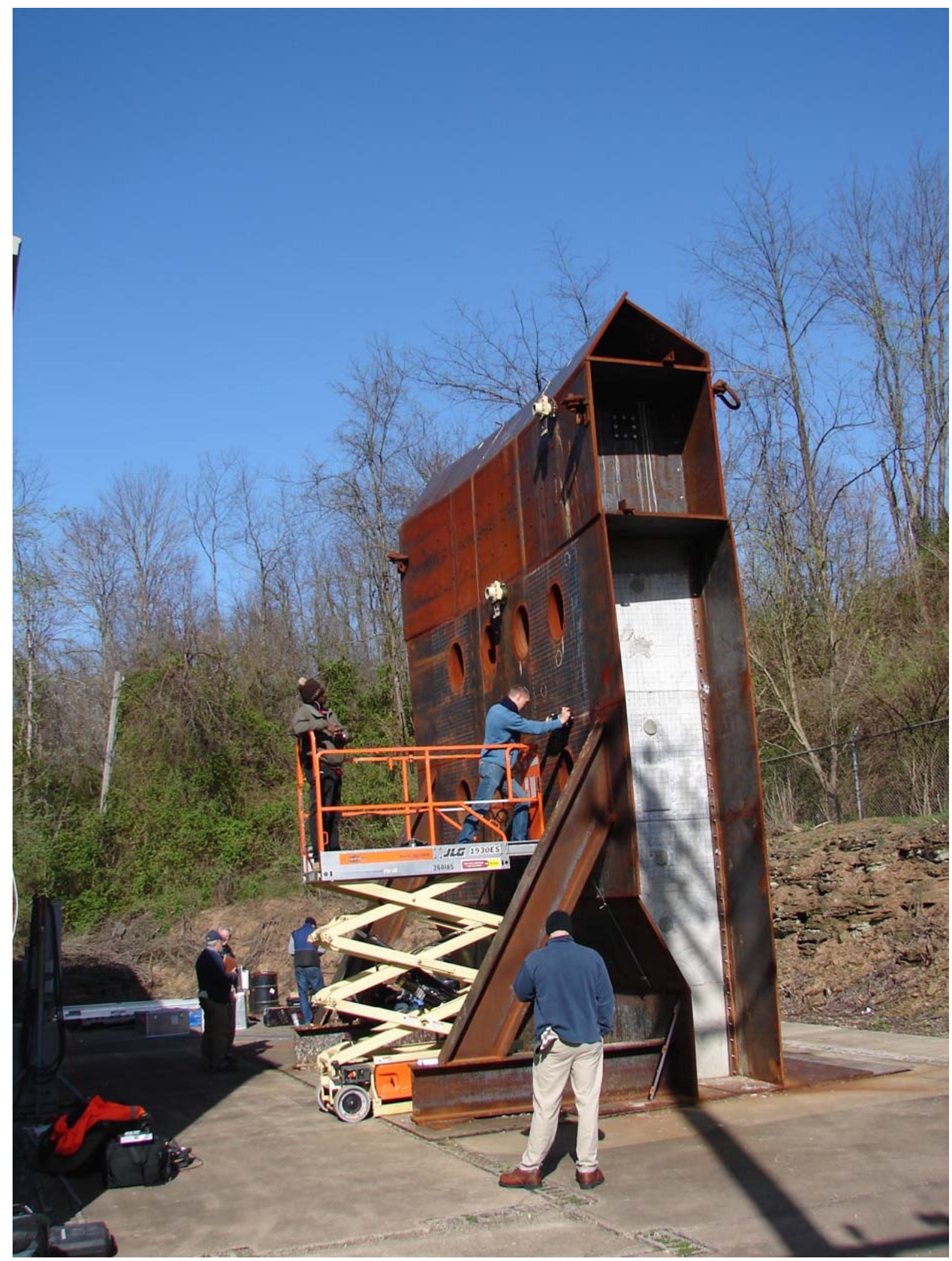

Figure 8. NDE Evaluations being performed on AP1000 Shield Building Section. 
The Shield Building section which WesDyne fabricated is the very top section of the Shield Building which contains the cooling ducts which cool the reactor in case of emergency. In Figure 3, this section is identified by the two BLUE horizontal arrows towards the top which indicate air flow. They choose to fabricate this section because of the interference that the cooling ducts will have on the flow of concrete into the section. All of the sections of the Shield Building below this section will be of the reduced thickness illustrated by the small length at the bottom of this section.

WesDyne evaluated the ultrasonic and impact-echo methods of NDE inspection on this fabricated section and they were able to detect the formed-in void simulations. However, there was also shrinkage of the concrete away from the steel inner and outer walls which was problematic for NDE inspection at those locations where shrinkage occurred.

Both of these concrete samples from WesDyne are available for NDE testing, technology evaluation and technician training, but their size is prohibitive for transporting them. The 3" x 3" x 10" specimen could be shipped by truck, but the 30" x 30" AP1000 Shield Building section would be impractical to ship by any means and would have to be used at its current location at WesDyne's Watts' Mill Service Center in Pittsburg, Pennsylvania. While both these samples are typical of AP1000 Shield Building construction, they are not typical of earlier nuclear power reactor shield building construction.

\subsection{FEDERAL HIGHWAY ADMINISTRATION NDE VALIDATION CENTER AT THE TURNER-FAIRBANK HIGHWAY RESEARCH CENTER [2] ${ }^{1}$}

The Federal Highway Administration (FHWA) NDE Validation Center is tasked with validating commercial concrete NDE systems for use by state inspectors on highway structures. Their tasking was established by the National Bridge Inspection Program (NBIP) through the Federal Highway Act of 1968 which required states to periodically inventory and inspect all highway structures on the federal aid system. Since then, Congress has expanded this inspection program to include all structure on public roads including those not on the federal aid system. This mandate by Congress is the reason that states have their massive inspection, rating, and inventory programs.

While visual inspection has been the principal method for inspecting bridges, a number of NDE technologies such as infrared thermographic imaging, ground-penetrating radar imaging, laser-radar scanning, acoustic emission monitors, electromagnetic acoustic transducer, embedded corrosion microsensors, and last vibrometers are also being used. The NDE Validation Center was established by the FHWA in 1996 and is the only center in the world dedicated entirely to the evaluation and validation of NDE technologies for highway structures.

In August of 2008, a tractor-trailer fatally crashed through a bridge barrier on the William Preston Lane, Jr. Memorial Bridge in Maryland after a section of the bridge barrier was dislodged due to the impact. Investigations of this incident revealed significant corrosion of the anchor bolts which attached the bridge railing to the bridge deck. However, this corrosion was not visible during inspections before the accident. As a result, the FHWA NDE Validation Center has been investigation the feasibility of using four NDE technologies, ground penetrating radar (GRP), ultrasonic pulse-echo, digital radiography and infrared thermal imaging to develop bridge inspection method to augment visual inspections. To this end, the Center procured five specimens from Smith-Midland, a cast concrete products manufacturer in Midland, Virginia as shown in Table 1.

1 Photographs for Figures 9 through 20 have been supplied by Dr. Shane Boone of the FHWA NDE Validation Center at the Turner-Fairbank Highway Research Center 


\begin{tabular}{|c|l|l|}
\hline Specimen & \multicolumn{1}{|c|}{ Description } & \multicolumn{1}{c|}{ Defect } \\
\hline 1 & F-Shaped Free Standing Portable & Simulated Corrosion \\
\hline 2 & F-Shaped Bolt Down & Simulated Corrosion \\
\hline 3 & F-Shaped Free Standing Portable & Embedded Voids \\
\hline 4 & F-Shaped Bolt-Down & Embedded Voids \\
\hline 5 & Bridge Deck Slab & Embedded Voids \\
\hline
\end{tabular}

\section{Table 1. FHWA NDE Validation Center Specimens}

\subsubsection{Specimen 1 - F-Shaped Free Standing Portable with Simulated Corrosion}

Figure 9 shows the dimensions of Specimen 1 which is an F-shaped Free Standing Portable Barrier which is 12 feet long and 2 feet 8 inches high. This custom fabricated barrier has three specially prepared \#5 rebars through the middle of the barrier as well as wire mesh attached to the rebars. The 12 foot length of the barrier was segmented into six 2 foot sections as shown in the figure. Over each 2 foot section of rebar, the diameter was machined to simulate different levels of corrosion as identified in Table 2 and shown in Figure 10.

\begin{tabular}{|c|l|}
\hline Section Identification & Corrosion Simulation \\
\hline a & No Corrosion \\
\hline b & Mild Corrosion \\
\hline c & $5 \%$ Diameter Reduction \\
\hline d & $10 \%$ Diameter Reduction \\
\hline e & 25\% Diameter Reduction \\
\hline
\end{tabular}

Table 2. Corrosion simulation for each barrier section for Specimens 1 and 2.

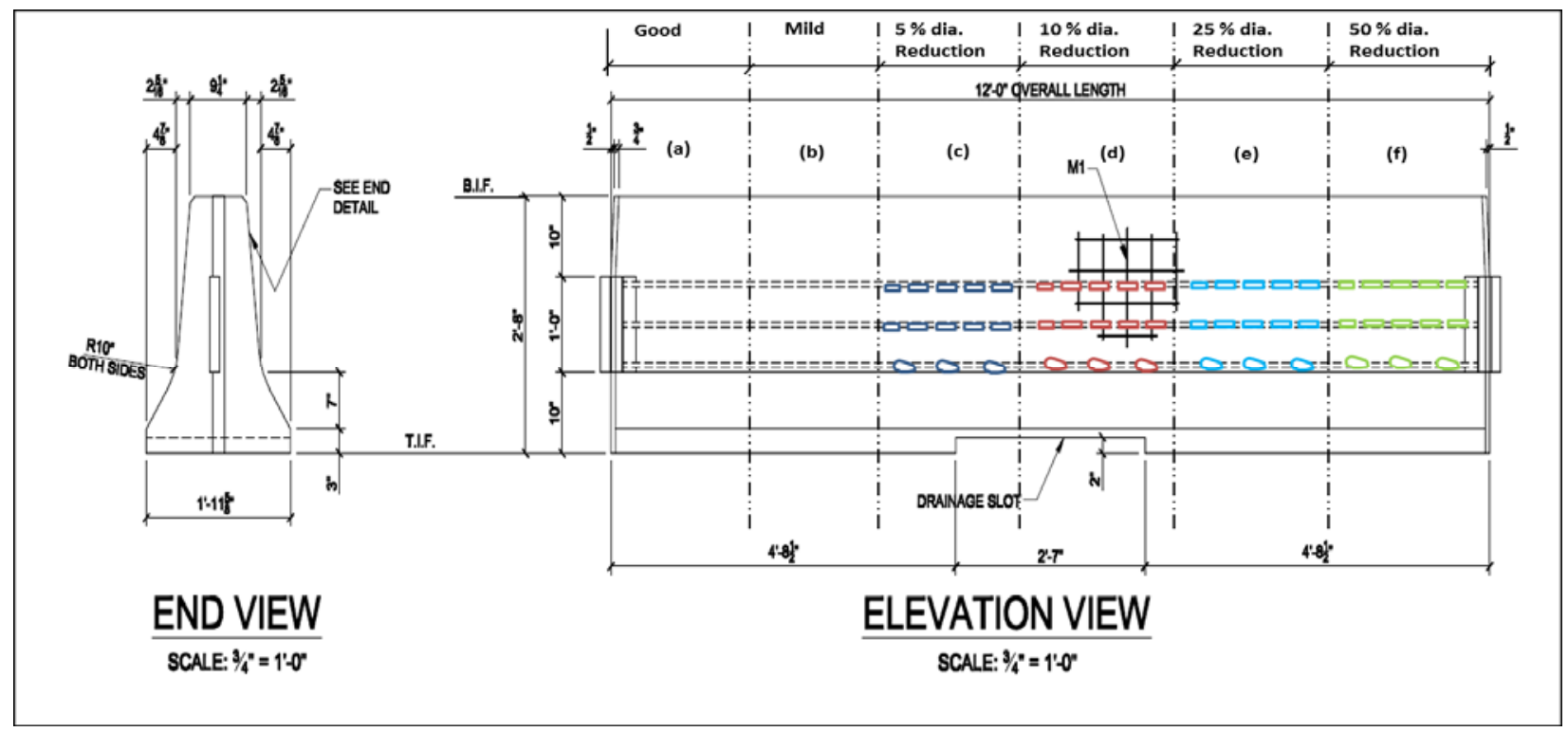

Figure 9. F-shaped free standing portable barrier. 

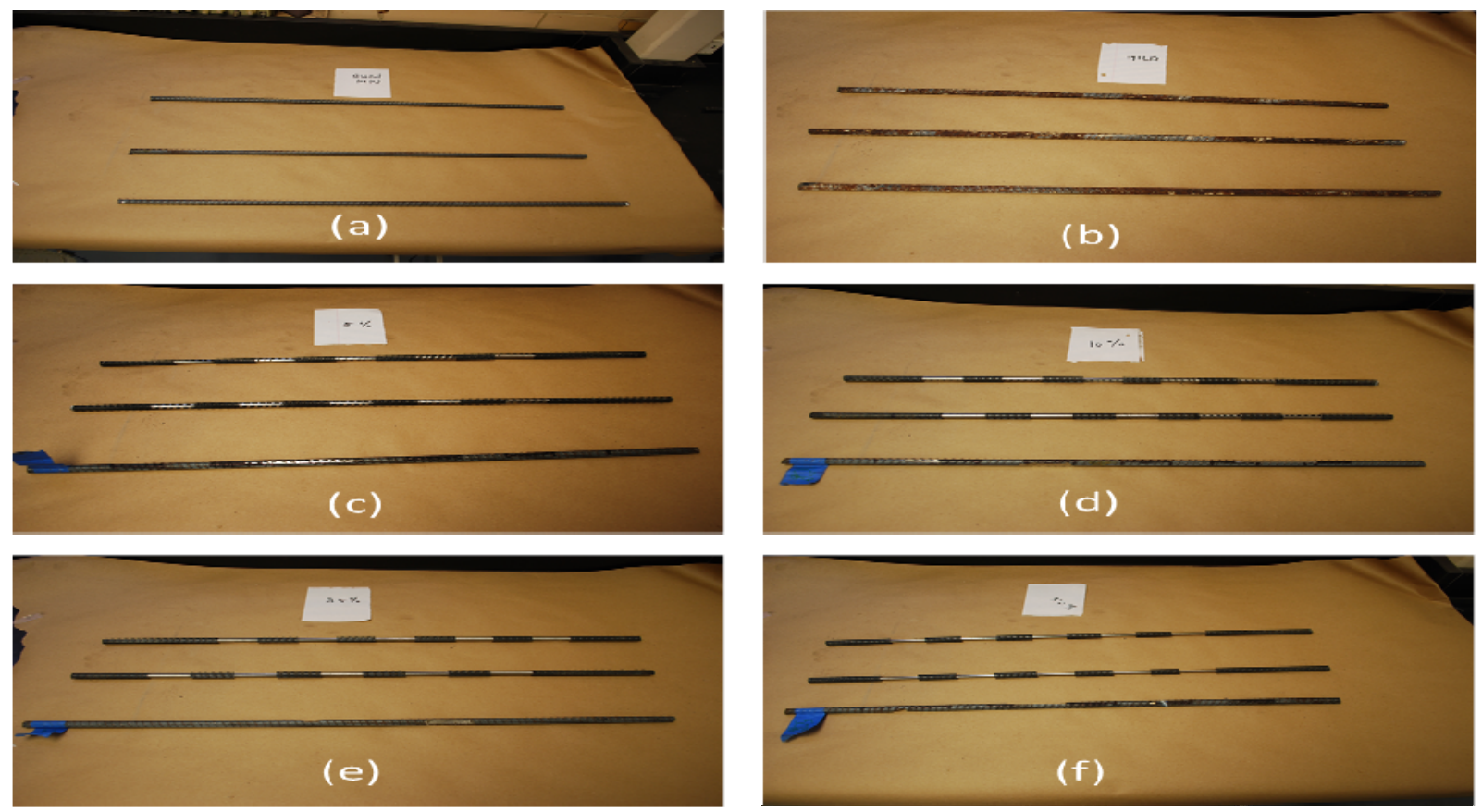

Figure 10. Different levels of simulated corroded.

\subsubsection{Specimen 2 - F-Shaped Bolt Down with Simulated Corrosion}

Figure 11 shows the dimensions of Specimen 2 which is an F-shaped Bolt Down Barrier which is 12 feet long and 2 feet 8 inches high. This custom fabricated barrier has three specially prepared \#4 rebars through the middle of the barrier and twelve U-shaped \#5 rebars placed every foot as shown in the end view of Figure 11. Photos of the U-shaped rebars are shown in Figure 12 and Figure 13. The 12 foot length of the barrier was segmented into six 2 foot sections as shown in the figure. All \#4 rebars were full diameter, but varying amounts of the diameter of the U-shaped rebars was machined to simulate different levels of corrosion as identified in Table 2.

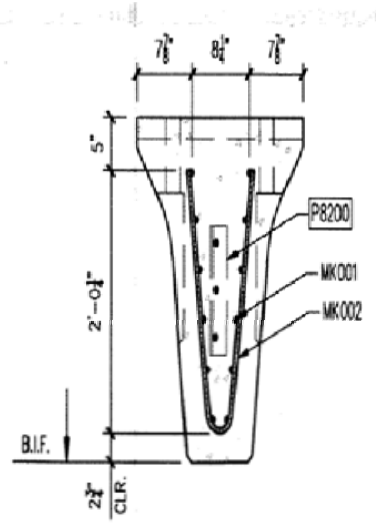

END VIEW

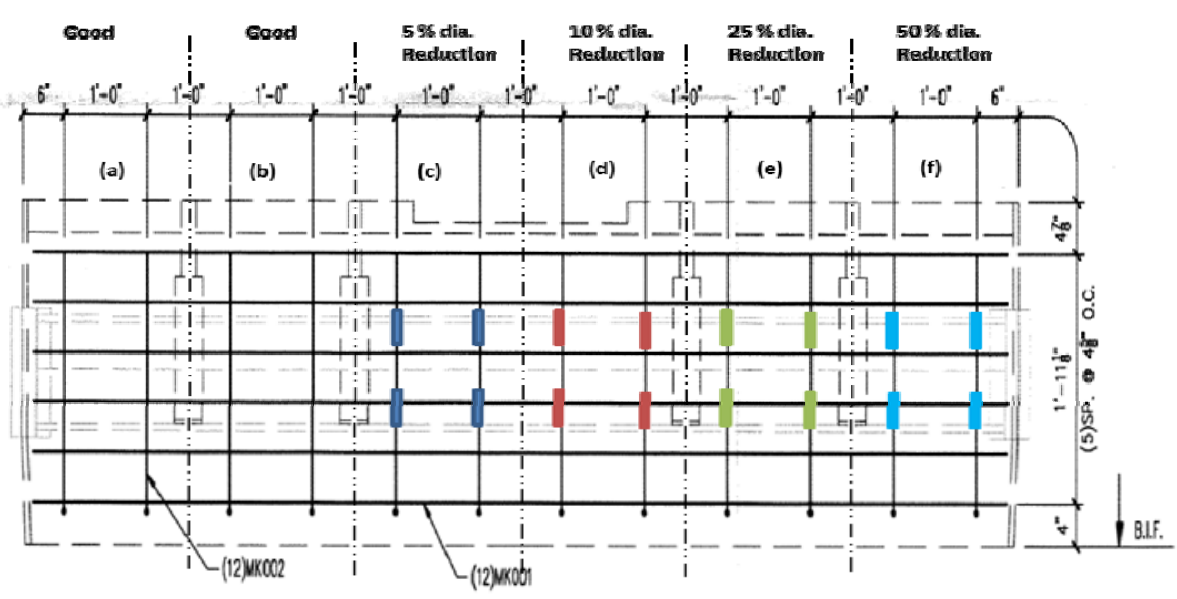

ELEVATION VIEW

Figure 11. F-shaped bolt-down barrier with different levels of simulated. 

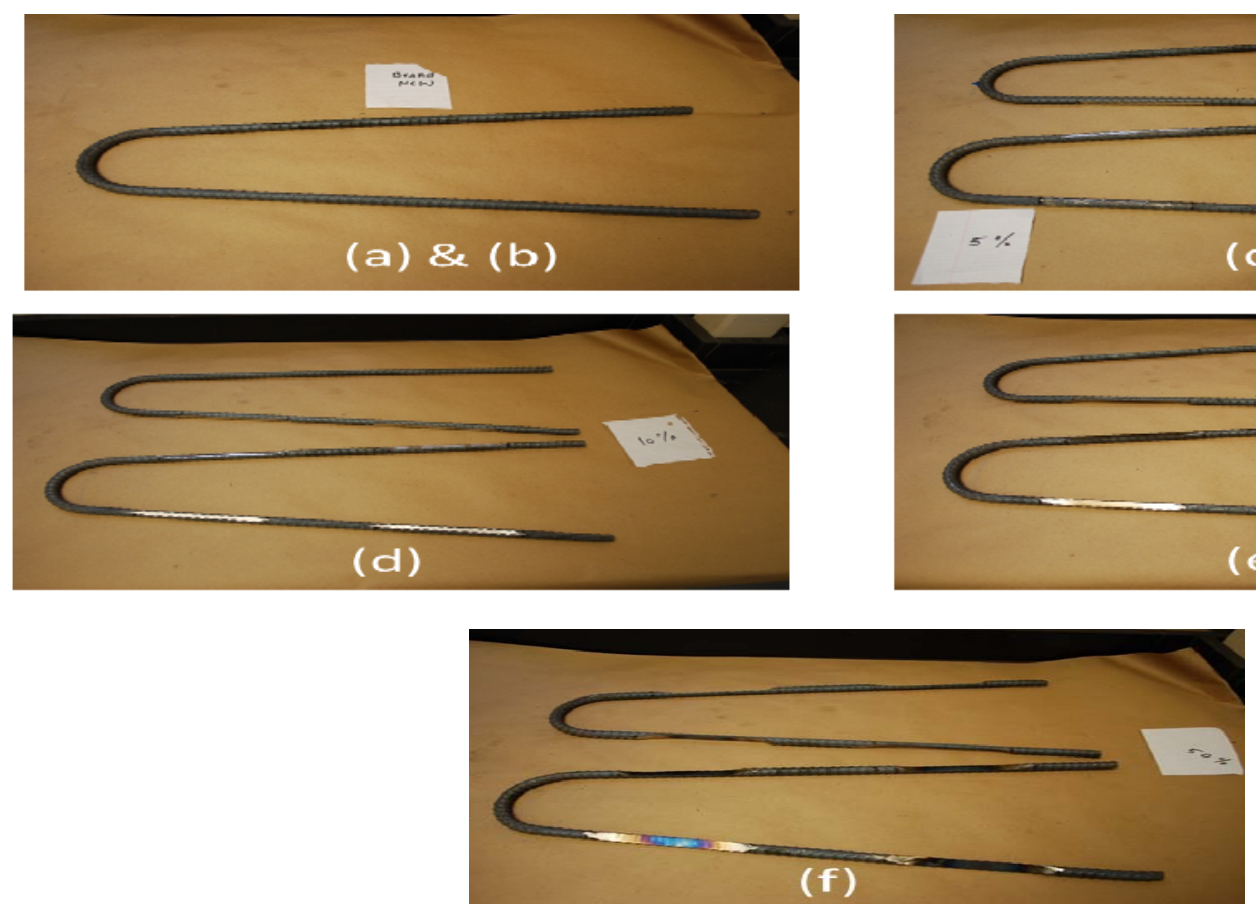

Figure 12. Different levels of simulated corroded U-shaped rebar.

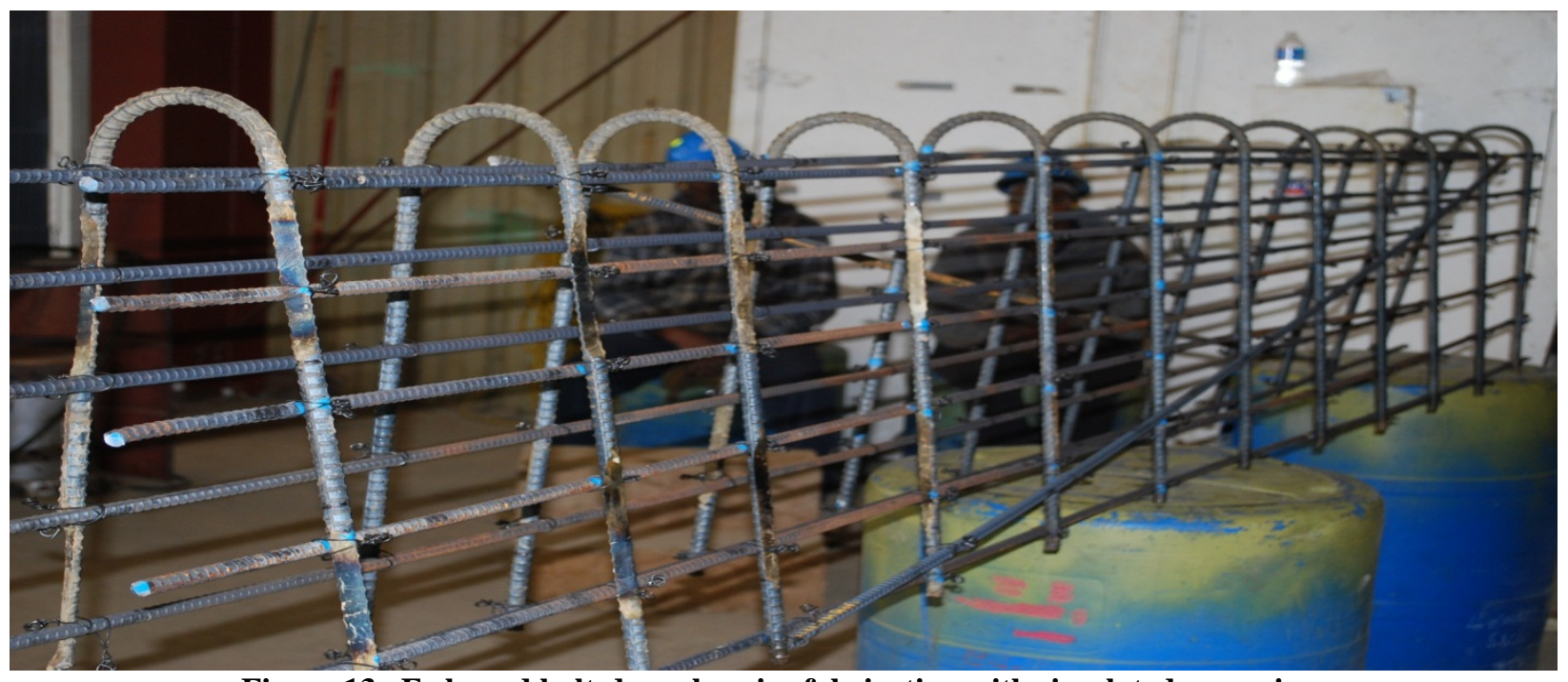

Figure 13. F-shaped bolt-down barrier fabrication with simulated corrosion.

\subsubsection{Specimen 3 - F-Shaped Free Standing Portable with Embedded Voids}

Figure 14 shows the dimensions of Specimen 3 which is an F-shaped Free Standing Portable Barrier which is 12 feet long and 2 feet 8 inches high. This custom fabricated barrier has three specially prepared \#5 rebars through the middle of the barrier as well as wire mesh attached to the rebars. The 12 foot length of the barrier was segmented into six 2 foot sections as shown in the figure. Over each 2 foot section of rebar, hollow balls, loose gravel and foam of different shapes and sizes were attached to the wire mesh to simulate voids, segregation, and delamination of different shapes and sizes respectively as identified in Table 3. Photo of F-shaped free standing portable barrier fabrication is shown in Figure 15. 


\begin{tabular}{|c|l|}
\hline Section Identification & \multicolumn{1}{|c|}{ Defect Simulation } \\
\hline a & Control \\
\hline b & Hollow balls to simulate voids \\
\hline c & Foam to simulate voids \\
\hline d & Foam to simulate delamination \\
\hline e & Foam balls to simulate voids \\
\hline f & Gravel to simulate segregation \\
\hline
\end{tabular}

Table 3. Defect simulation for each barrier section for Specimens 3 and 4.

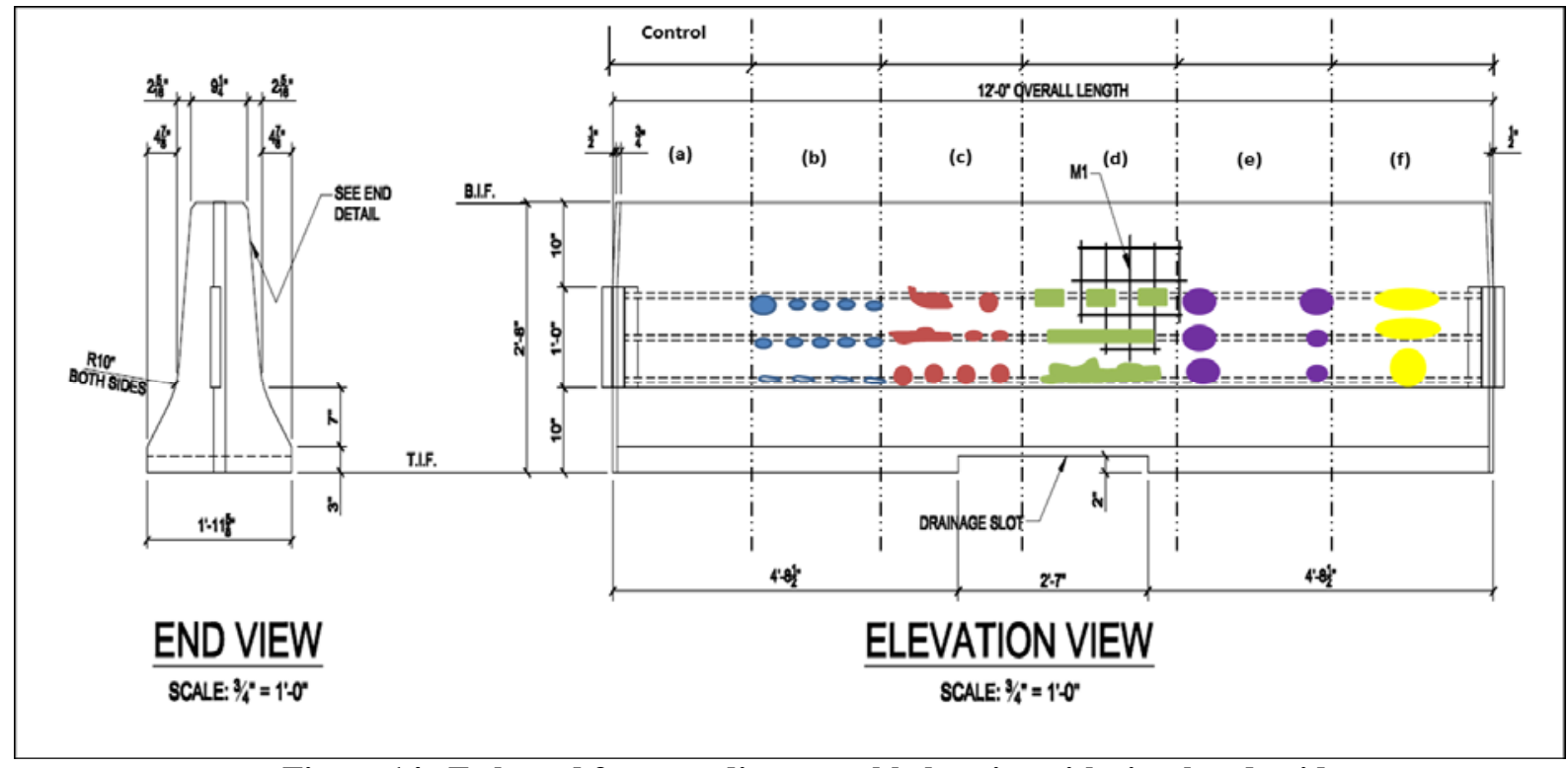

Figure 14. F-shaped free standing portable barrier with simulated voids.

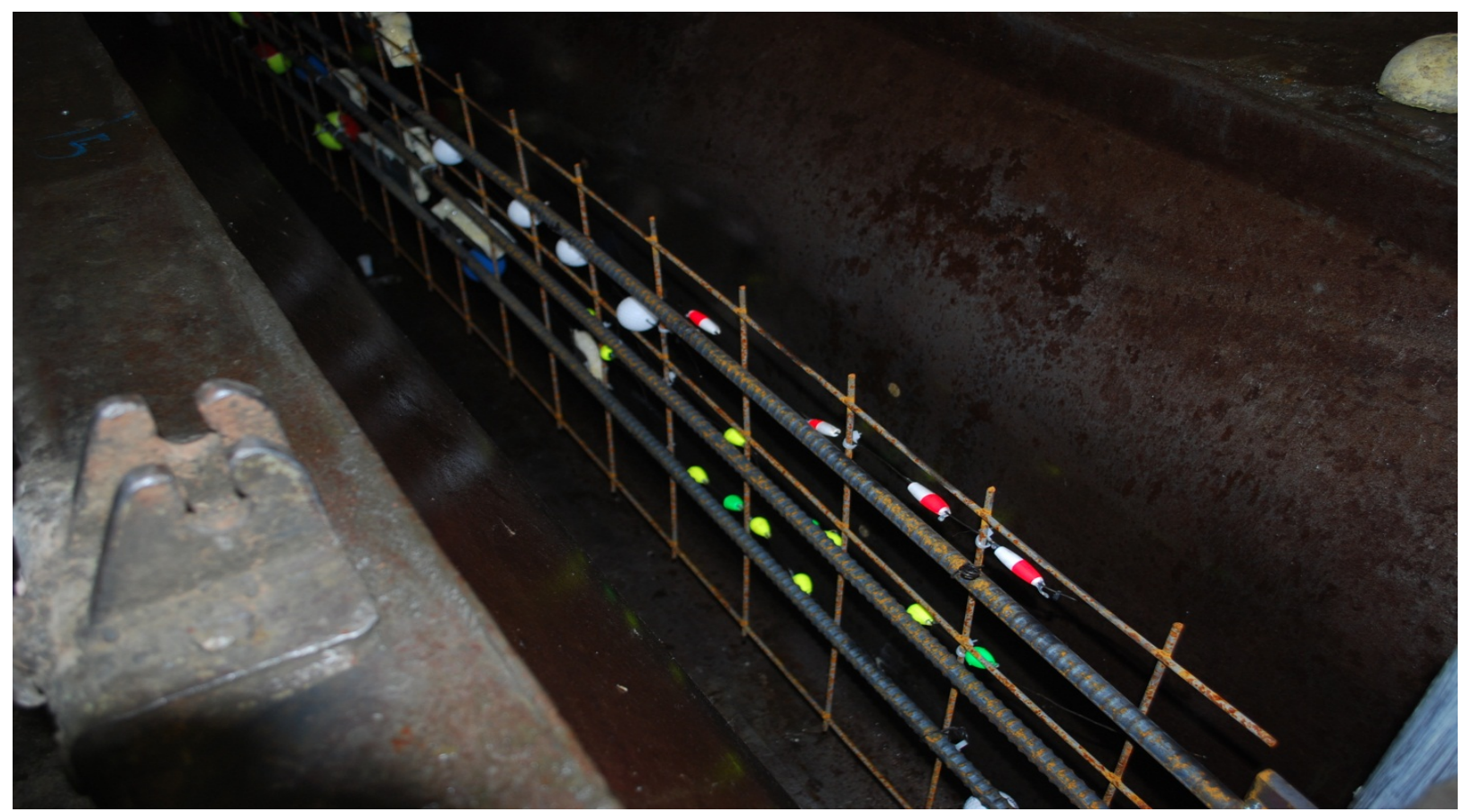

Figure 15. F-shaped free standing portable barrier fabrication. 


\subsubsection{Specimen 4 - F-Shaped Bolt Down with Embedded Voids}

Figure 16 shows the dimensions of Specimen 3 which is an F-shaped Bolt Down Barrier which is 12 feet long and 2 feet 8 inches high. This custom fabricated barrier has three specially prepared \#4 rebars through the middle of the barrier and twelve U-shaped \#5 rebars placed every foot as shown in the end view of Figure 16. The 12 foot length of the barrier was segmented into six 2 foot sections as shown in the figure. In each section, hollow balls, loose gravel and foam of different shapes and sizes were attached to the \#4 rebar to simulate voids, segregation and delamination of different shapes and sizes respectively as identified in Table 3. Photo of F-shaped bolt-down barrier fabrication with embedded simulated flaws is shown in Figure 17.

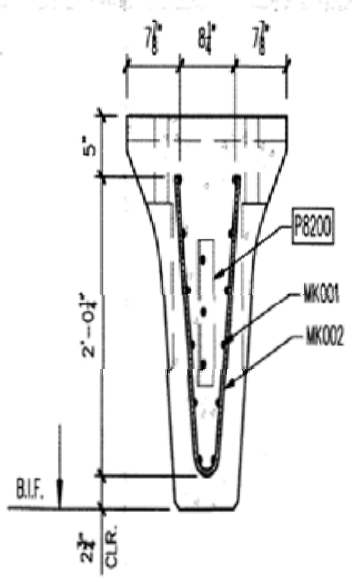

END VIEW

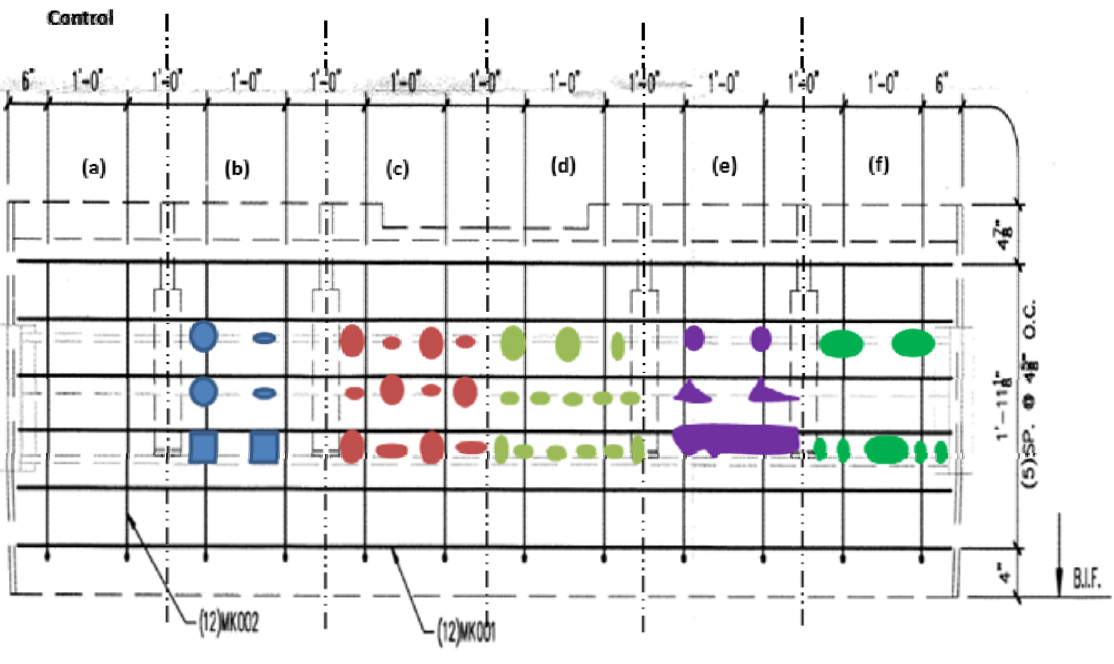

ELEVATION VIEW

Figure 16. F-shaped bolt-down barrier with different levels of simulated voids.

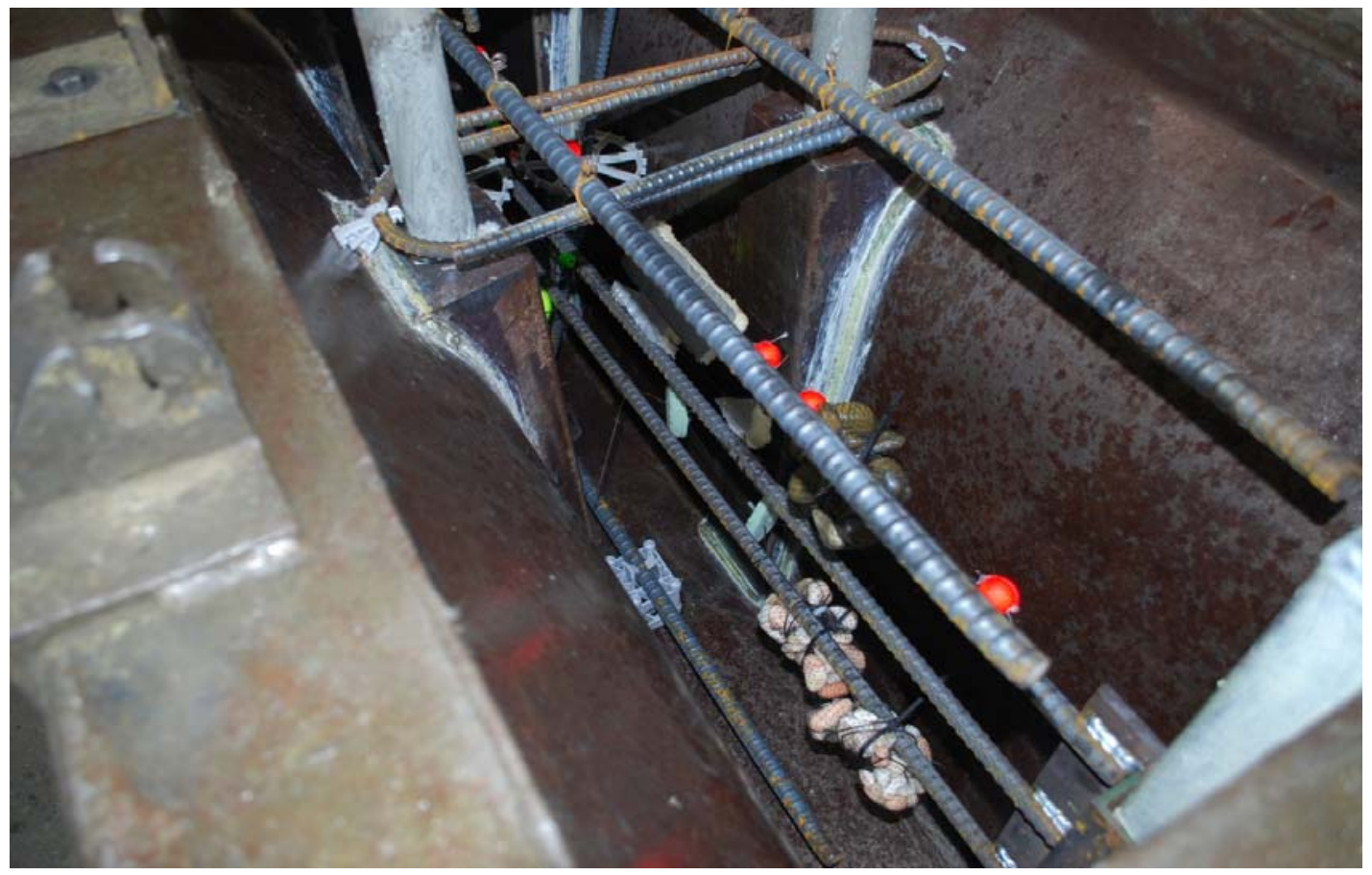

Figure 17. F-shaped bolt-down barrier fabrication with embedded simulated flaws. 


\subsubsection{Specimen 5 - Bridge Deck slab with Embedded Voids}

Reinforced concrete barriers are anchored using reinforcing steel or anchoring bolts protruding from the main structure. Corrosion damage reduces the bolt diameter and cross section. The FHWA NDE Center fabricated a 12' x 8' x 8' simulated bridge deck with included flaws as shown in Figure 18 to use in testing the barriers previously described. This bridge deck containing defects is a specimen into itself. The barriers for testing will be attached to this specimen using four \#5 rebars with different levels of simulated corrosion as shown in Figure 19. Simulation of corrosion will be accomplished by machining away varying amounts of the reinforcing steel's diameter; (1) Control, (2) 10\% Diameter, (3) 25\% Diameter, and (4) 50\% Diameter. A barrier specimen attached to the bridge deck slab specimen is shown in Figure 20.

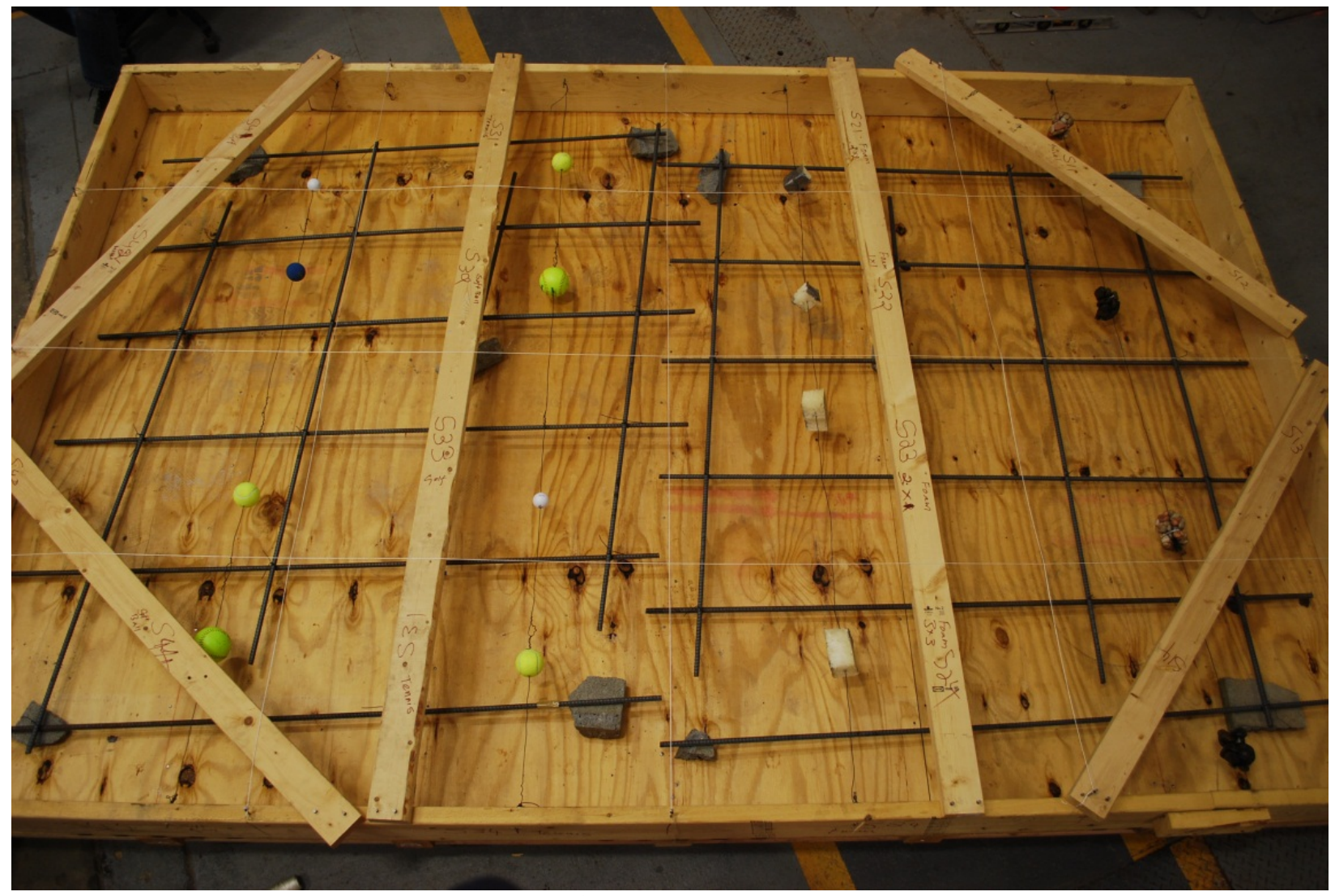

Figure 18. Embedded flaws in the mock up bridge deck slab. 


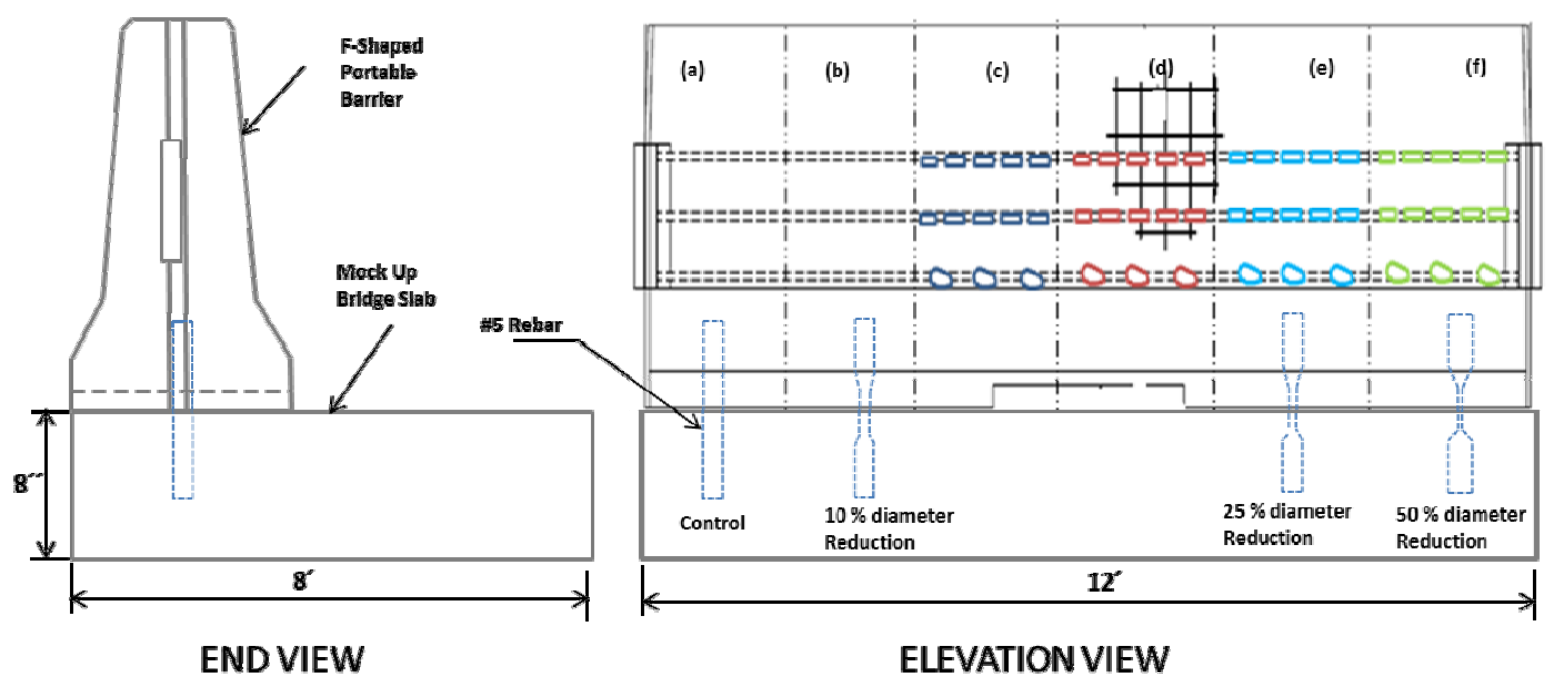

Figure 19. Schematic of mock up bridge deck with attached concrete barrier.

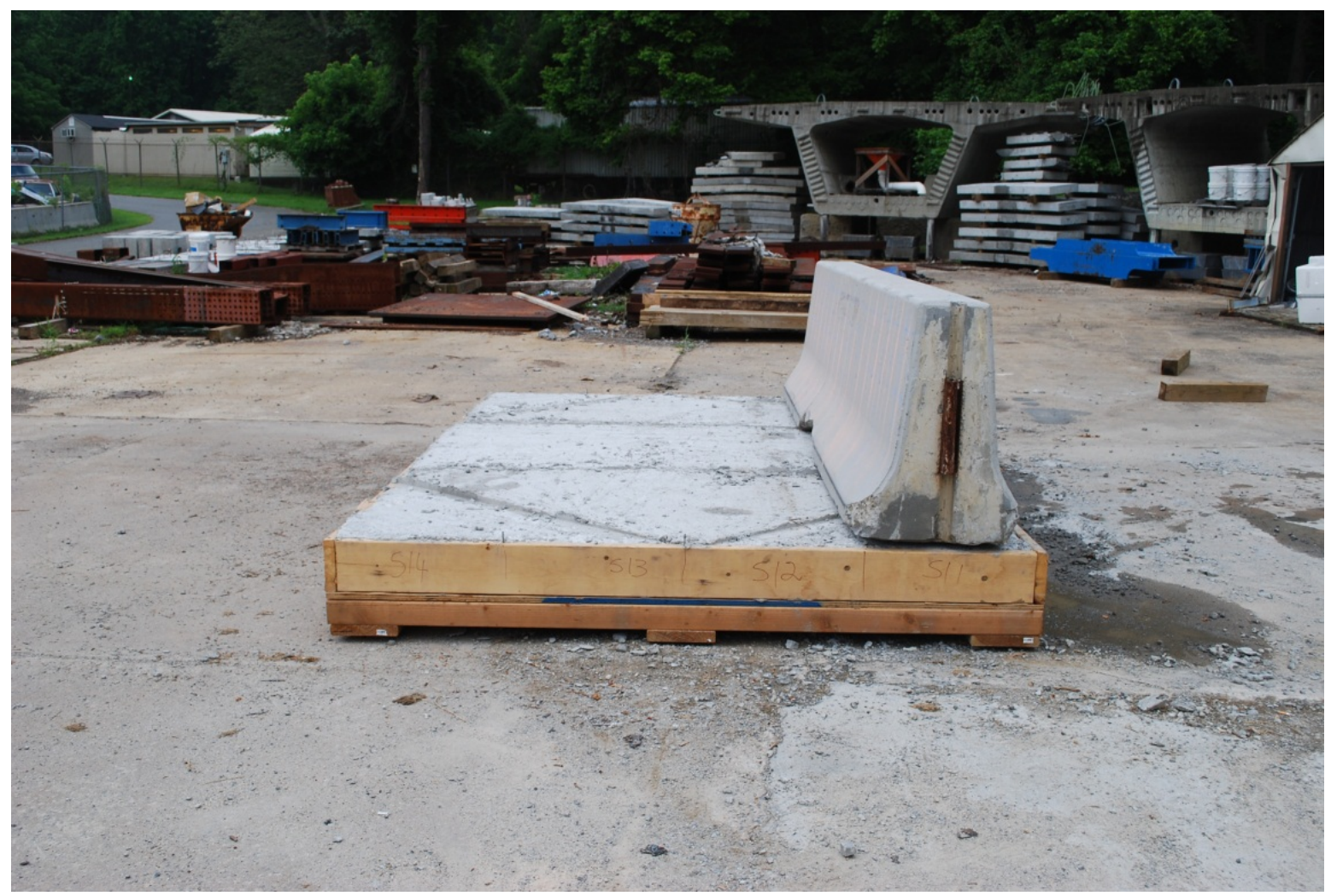

Figure 20. Concrete barrier anchored to mockup bridge deck slab.

\subsubsection{Specimen 6 - Other Specimens}

The FHWA NDE Validation Center has many concrete test specimens that are used for various purposes including NDE technique evaluation and validation. One such specimen shown in Figure 21 is the Fshaped Bolt Down Barrier mentioned above which has simulated voids, delaminations and segregation. Ground penetrating radar equipment along with phased array ultrasonic equipment is typically utilized on 
this specimen. The application of ground-penetrating radar equipment on this specimen is shown in Figure 22 while the resulting output display which illustrates the internal location of the steel reinforcement bars is shown in Figure 23. The application of the phased array ultrasonic equipment on this specimen is shown in Figure 24 and the resulting output display which illustrates the location of a line of voids as well as the opposing face of the barrier and the width of the barrier is illustrated in Figure 25.

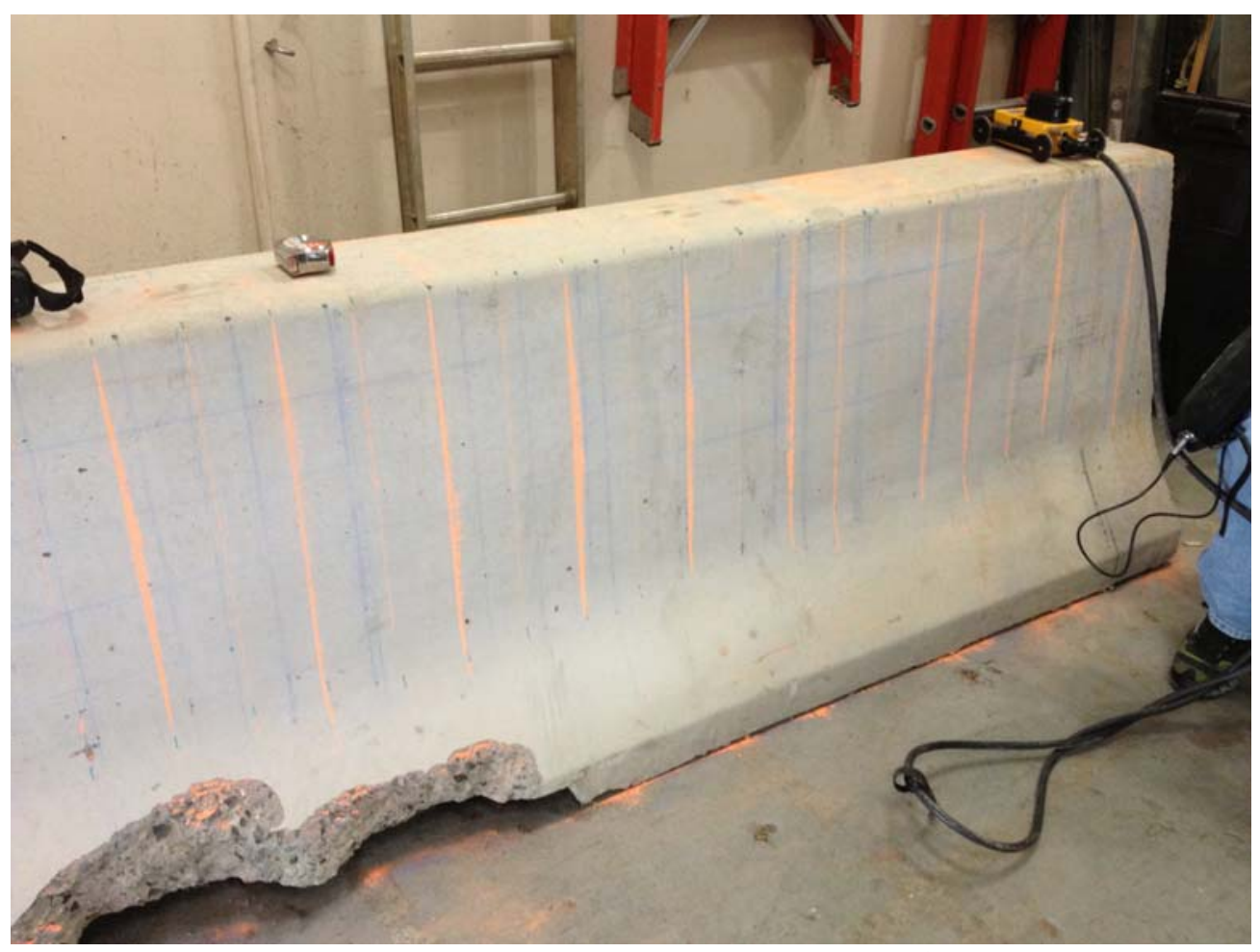

Figure 21. Barrier specimen with various steel reinforcement. 


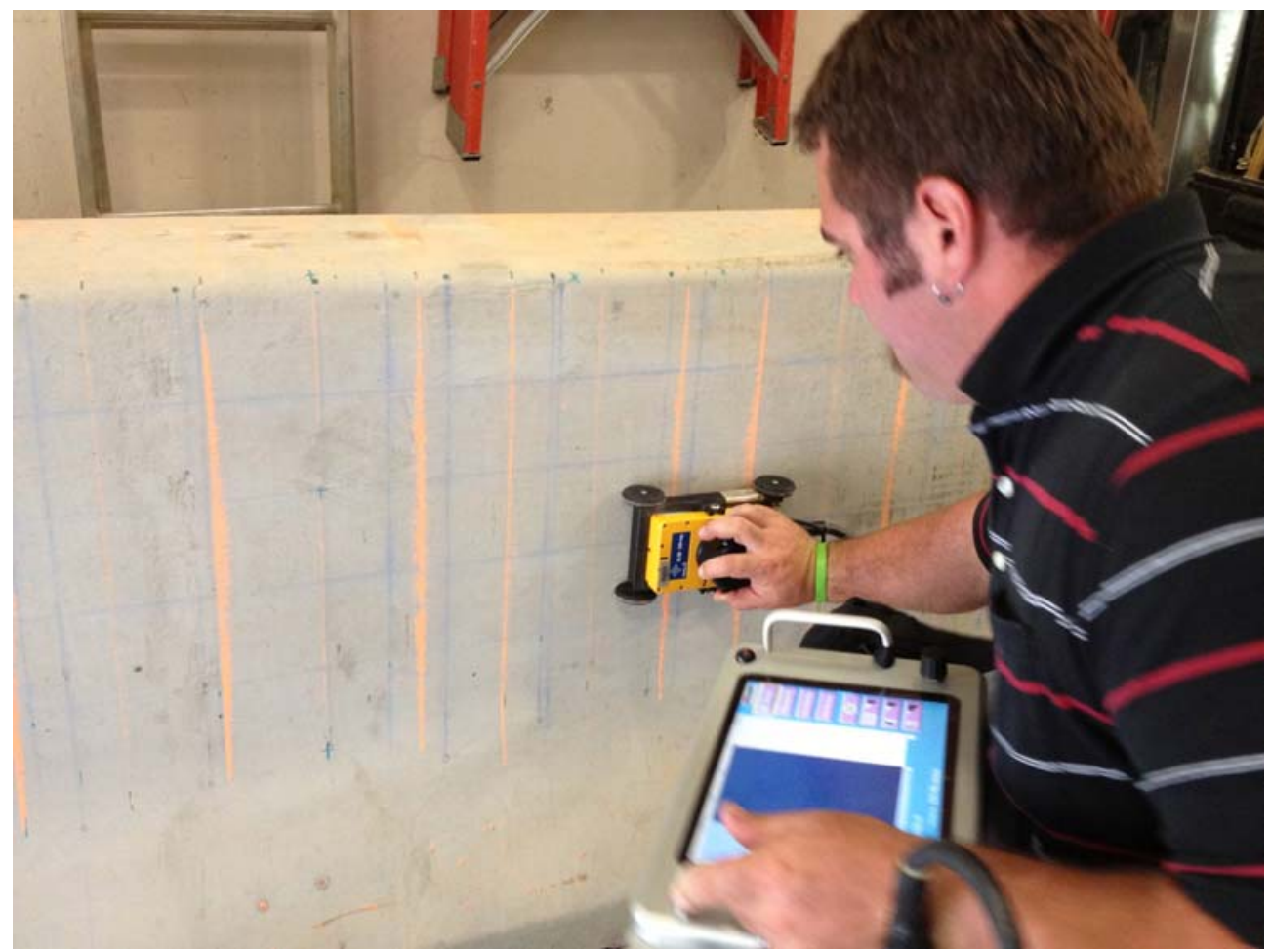

Figure 22. Use of ground-penetrating radar on barrier concrete specimen.

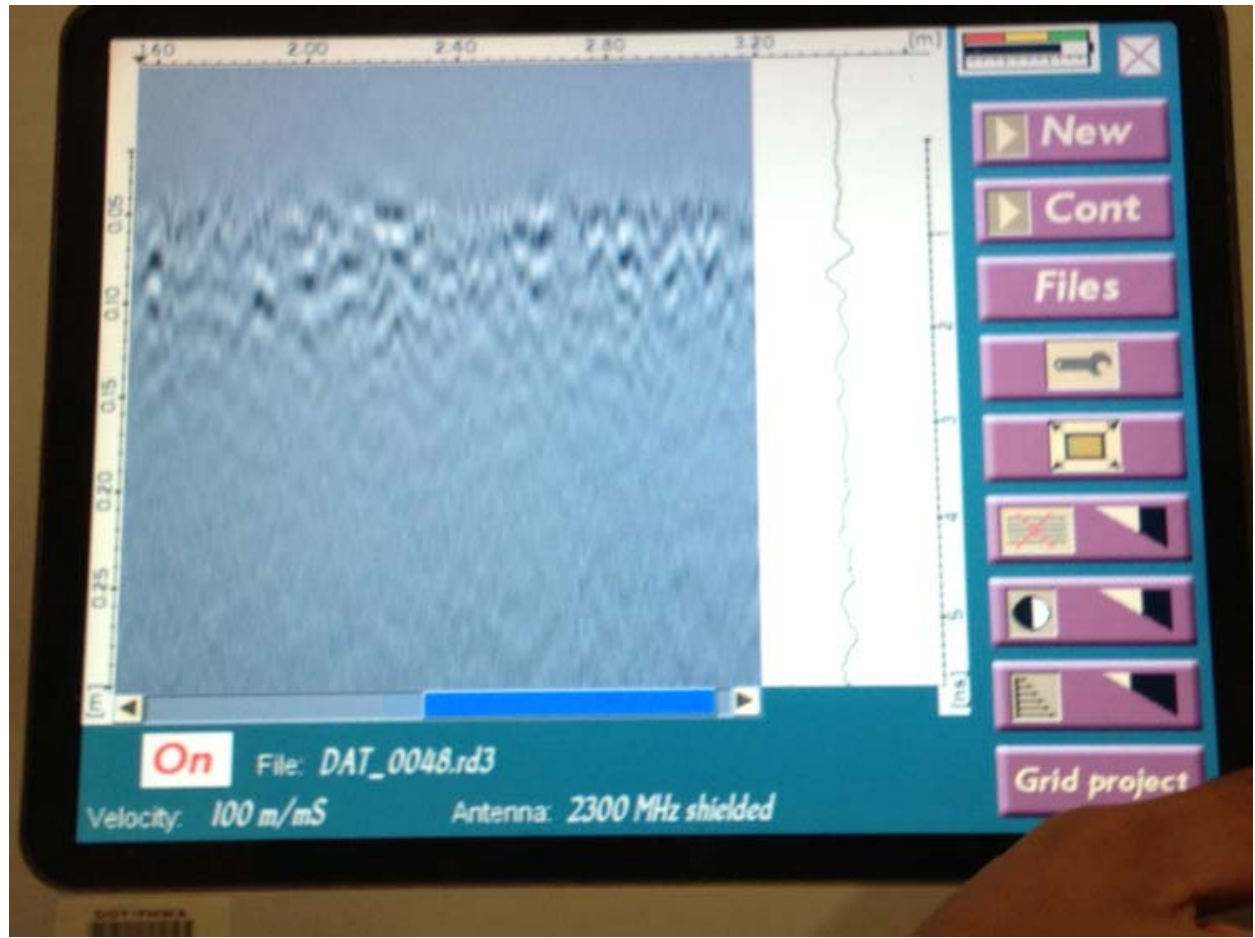

Figure 23. Ground-penetrating radar instrument output. 


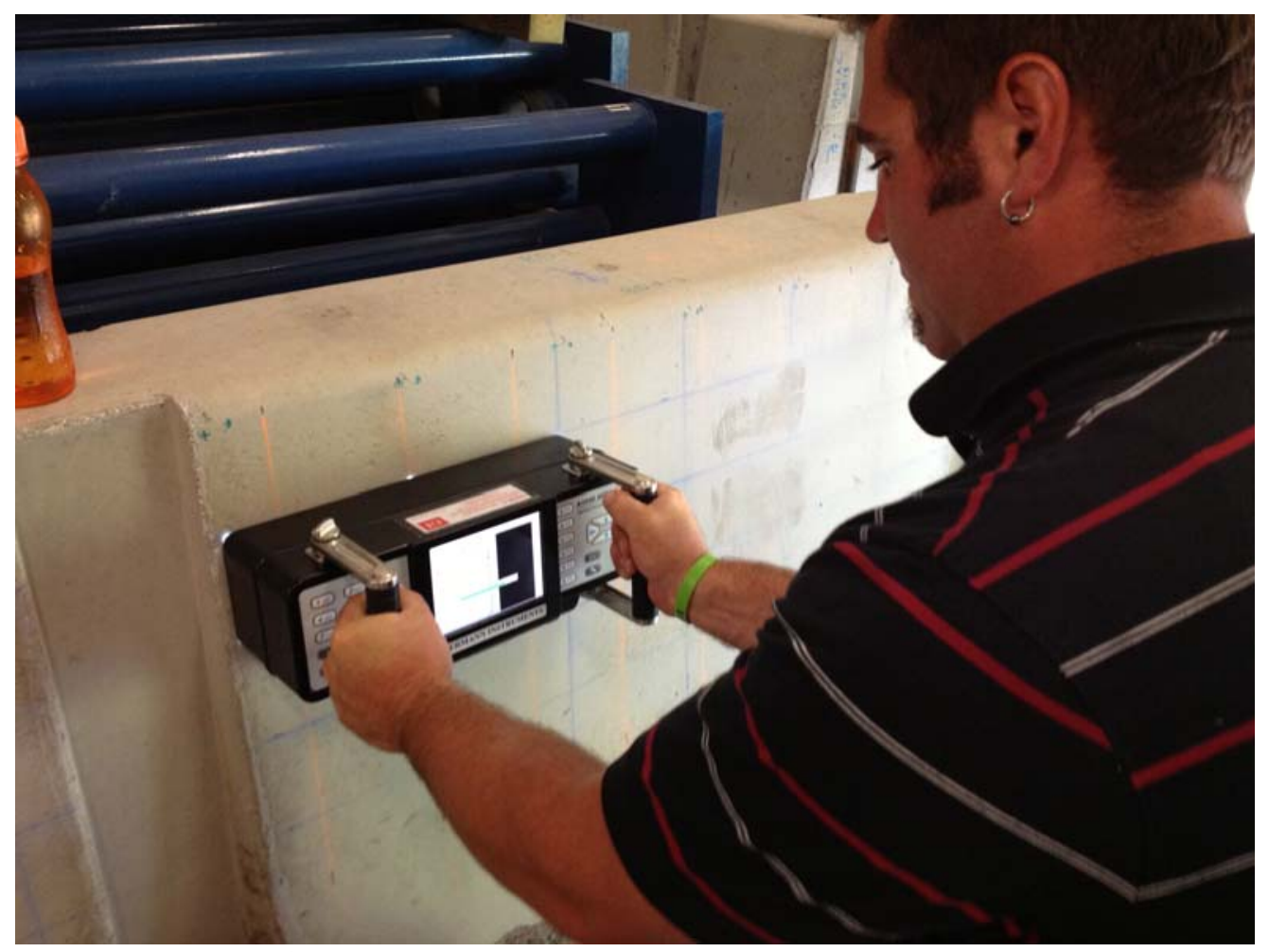

Figure 24. Use of phased array ultrasonic equipment on barrier concrete specimen.

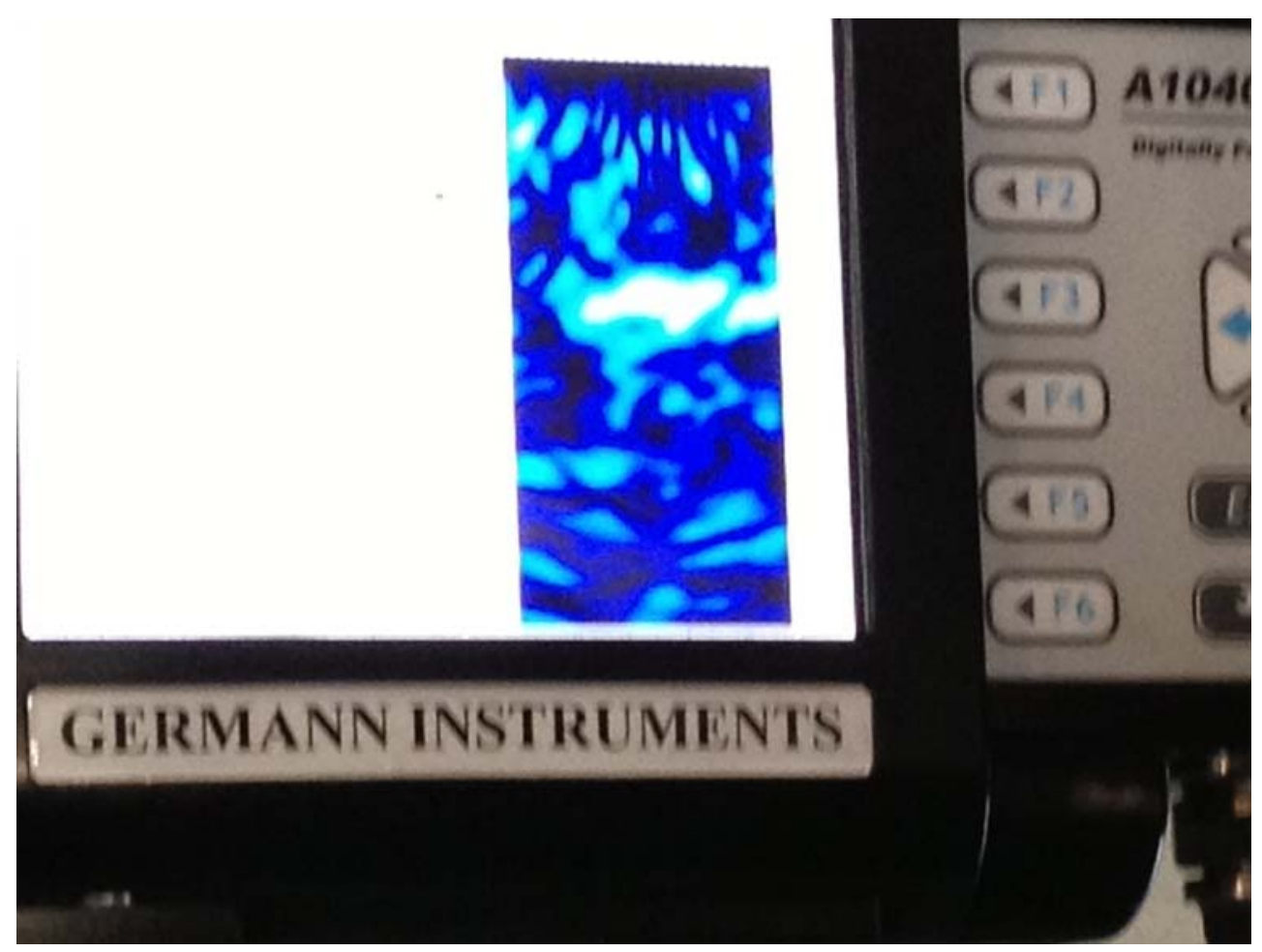

Figure 25. Phased array ultrasonic instrument output. 
The FHWA Validation Center also has access to specimens of large pre-stressed bridge sections as show in Figures 26 and 27. These specimens are more representative of the cross sectional thicknesses of nuclear power plant concrete structures (without the heavy steel reinforcement), but they have been formed from pre-stressed high performance concrete instead of continuous poured self-consolidating concrete. The particular specimens shown in the photos are undergoing steel reinforcement corrosion testing which is of interest to the nuclear power plant industry.

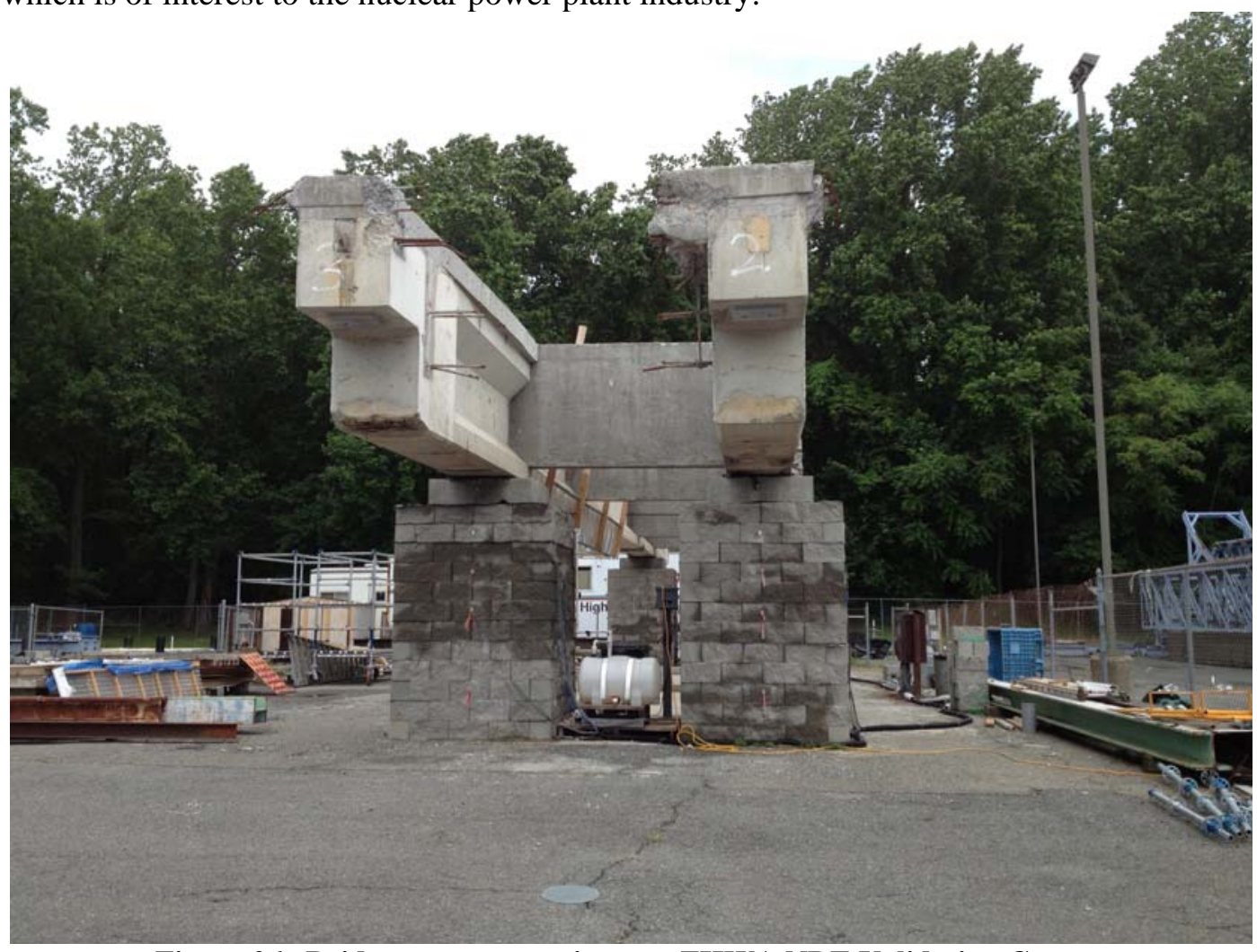

Figure 26. Bridge support specimen at FHWA NDE Validation Center. 


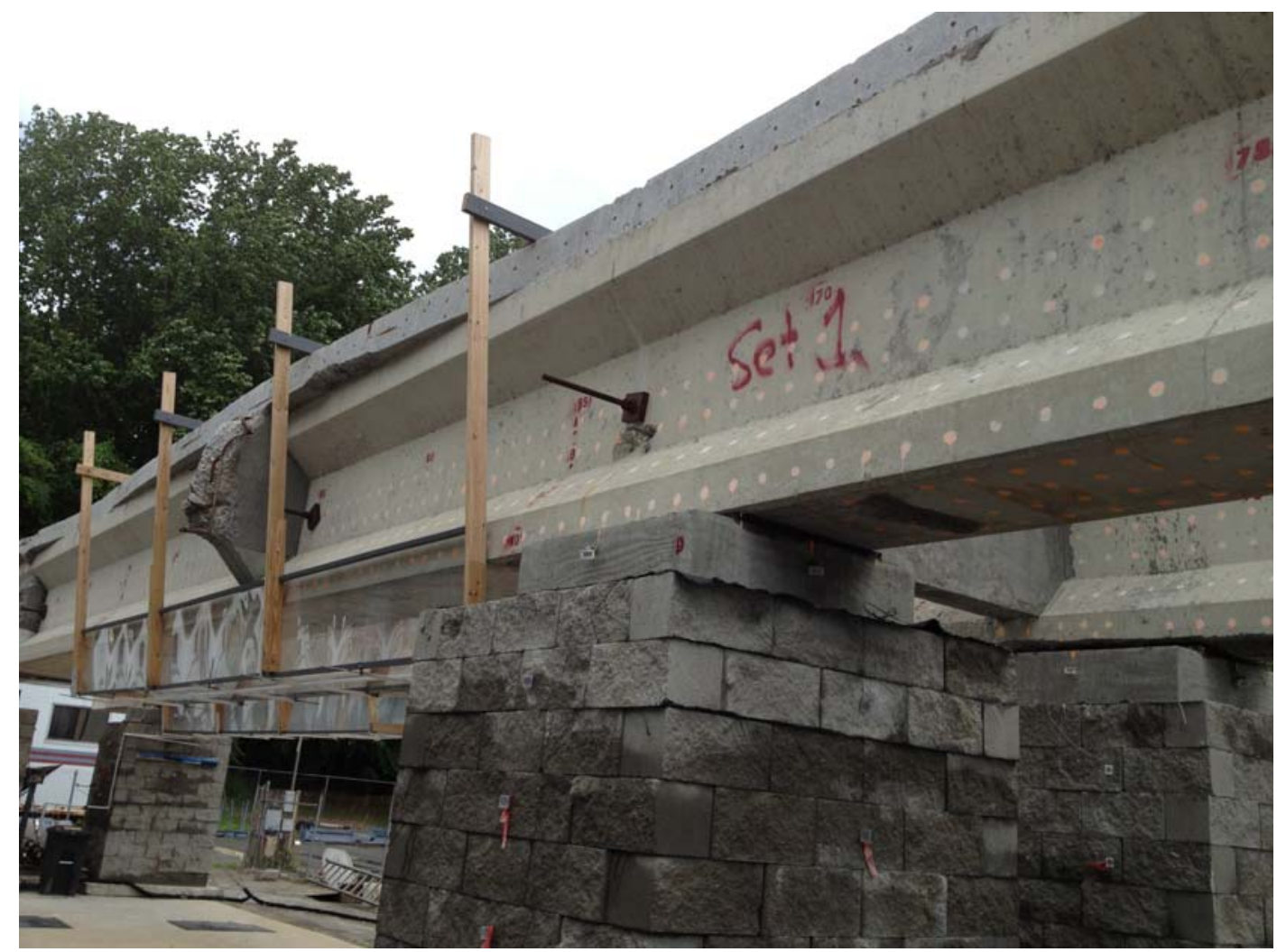

Figure 27. Bridge support specimen undergoing steel reinforcement corrosion testing.

The FHWA NDE Validation Center also has a variety of additional specimens which can be used for NDE research and testing. Some of these are roadway bridge deck sections which are shown in Figure 28 and are only about 12 inches thick by 5.5 feet wide by 11.5 feet long. There are also some high performance concrete sections with extensive reinforcement as shown in Figure 29. 


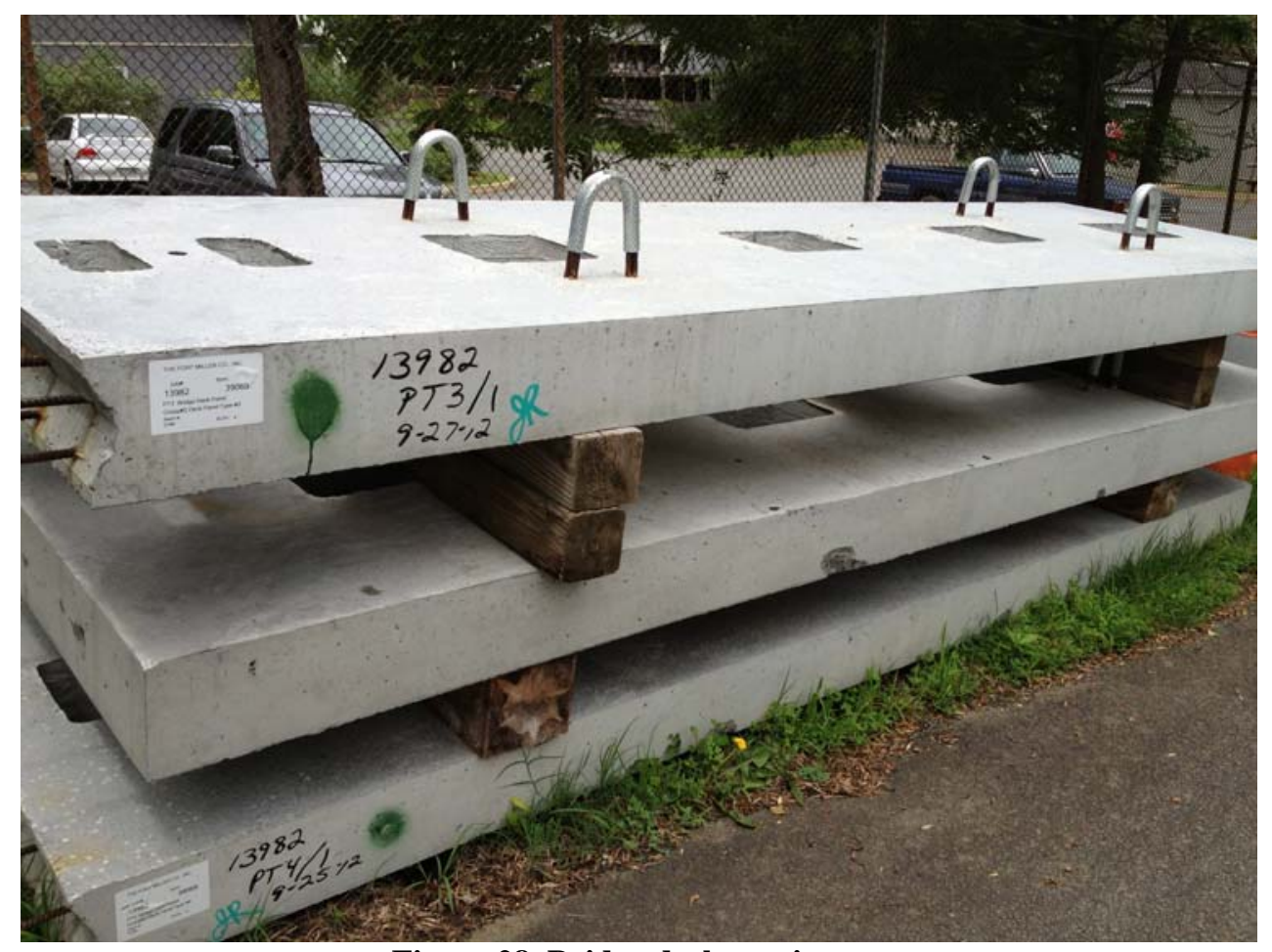

Figure 28. Bridge deck specimens.

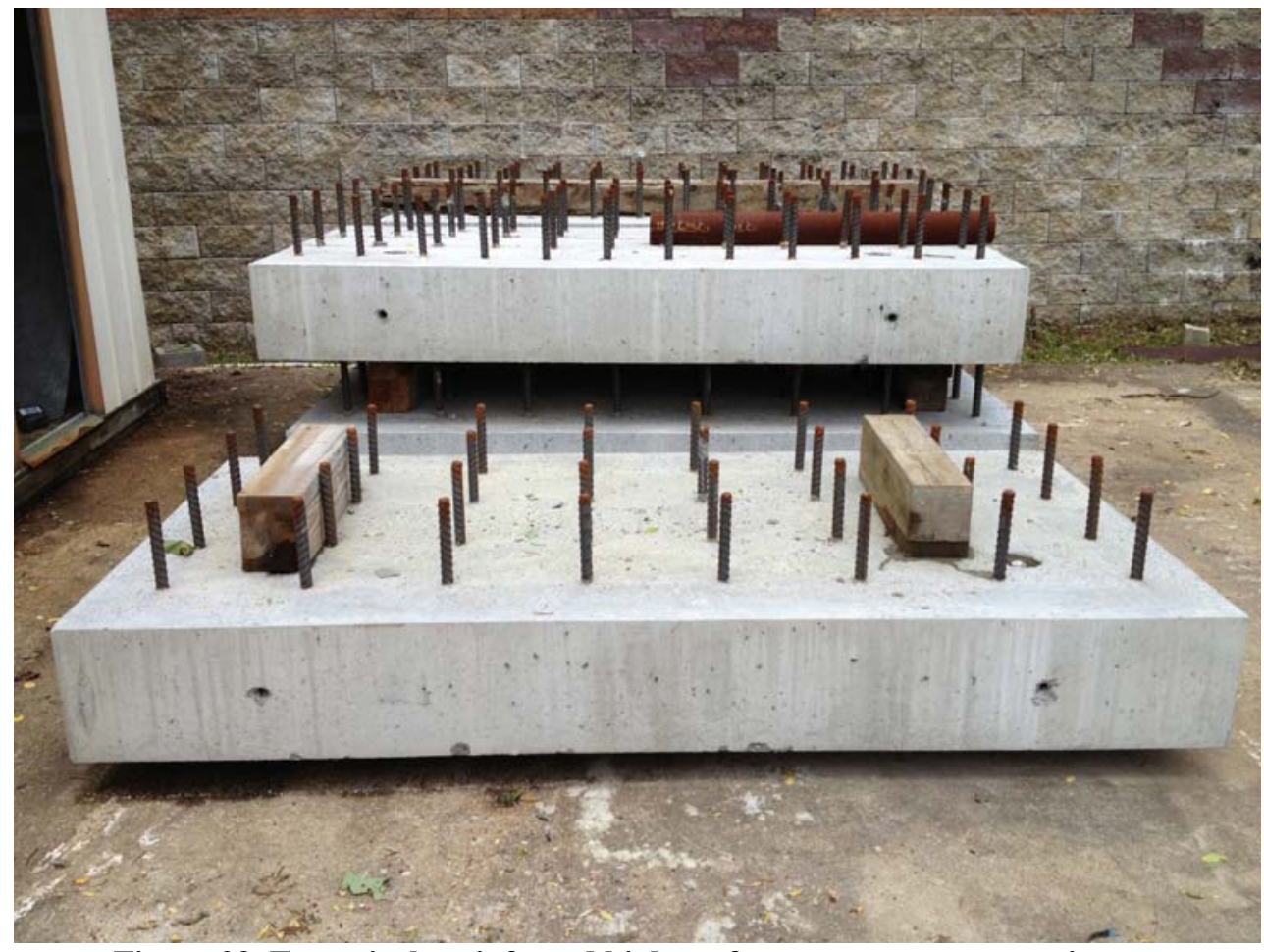

Figure 29. Extensively reinforced high performance concrete specimens.

The specimens at the FHWA Validation Center are also available for NDE research. Some are such that they could be shipped around whereas others are too large and would have to be utilized on location in McLean, Virginia. Some of the large bridge structures specimens located here are the closest in cross 
sectional thickness to structures in the nuclear power plant, but they are not as heavily reinforced and the steel reinforcement significantly impacts some NDE methods.

\subsection{THE FLORIDA DEPARTMENT OF TRANSPORTATION NDE VALIDATION FACILITY IN CONJUNCTION WITH THE DEPARTMENT OF CIVIL AND COASTAL ENGINEERING UNIVERSITY OF FLORIDA, GAINESVILLE [3] ${ }^{2}$}

The Florida Department of Transportation (FDOT) has needs to address durability problems with Portland cement concrete in structural applications. While the desired design life for bridges in Florida is now 100 years, the production of concrete for these significant design periods is rather challenging. One of the biggest problems in Florida affecting durability is the corrosion of reinforcing steel due to infiltration of concrete with salt water, which is particularly a problem for structures located in coastal areas, e.g. Miami and Tampa. Infiltration and corrosion is not typically a result of design mistakes, but rather a product of flaws induced during construction. These flaws include inadequate cover due to improper placement of steel reinforcement, inconsistent consolidation which can result in debonding and air pockets near reinforcement, and surface cracks due to improper finishing, curing, etc. All of these flaws are likely to accelerate infiltration and corrosion.

Traditionally, the inspection and acceptance of facilities constructed of structural concrete is based upon visual surveys and results from traditional tests on concrete samples, e.g. slump, cylinder breaks, etc. However, the FDOT has moved toward implementation of nondestructive test and evaluation (NDT/NDE) technologies to assess quality of concrete constructed in the field as means to reduce flaws introduced by faulty construction. An efficient application of such methods can lead to improved quality of concrete construction, improved durability and longer life, and significant cost savings for the state of Florida. To be implemented, these technologies must be proven to be effective, and this proof is developed via calibration and validation research experiments in which the technologies are shown to be accurate and reliable in circumstances where the result (i.e., concrete characteristics as well as the size and position of objects, such as reinforcing steel, tendon ducts or voids inside the concrete) is well known. Several years ago, FDOT established the FDOT NDE Validation Facility at their State Materials Office (SMO) in Gainesville in conjunction with the Department of Civil and Coastal Engineering, University of Florida, Gainesville.

The validation of NDE techniques in Florida began with the use of four specially fabricated test concrete block specimens sized 6.5 feet by 5 feet with a thickness of up to 20 inches. Two additional test blocks were procured from the FDOT Structures Office in Tallahassee which had been previously fabricated to validate NDE techniques to detect broken strands of post tensioning cable within the grout in the tendon ducts. Finally, a seventh block of similar size to the first four blocks was fabricated with more difficult to detect fabrication flaws. A summary of the seven test blocks is given in Table 4.

2 Photographs in Figures 30 through 46 and the basis for the text in this section have been supplied by Dr. Chris Ferraro and Mr. Jordan Nelson of the Florida Department of Transportation and the University of Florida, Department of Civil and Coastal Engineering. 


\begin{tabular}{|c|c|c|}
\hline Specimen & Description & Size \\
\hline 1 & Control Block - Uniform concrete - No Known Defects & $6.5^{\prime} \times$ 5’ x 10” \\
\hline 2 & $\begin{array}{l}\text { Reinforcement Bar - Various sized rebar and spacing - front } \\
\text { and back- vertically, horizontally, and depth }\end{array}$ & $6.5^{\prime} \times 5^{\prime} \times 10^{\prime \prime}$ \\
\hline 3 & $\begin{array}{l}\text { Varying Thickness - Six different equally sized thickness areas } \\
\text { - two different sized cutouts for edge effects study in nominal } \\
\text { thickness }\end{array}$ & 6.5’ x 5' x Various \\
\hline 4 & $\begin{array}{l}\text { Tendon Duct - Two different sized ducts each size both } 1 / 2 \text { filled } \\
\text { and } 3 / 4 \text { filled with grout - all ducts not parallel to any block edge }\end{array}$ & $6.5^{\prime} \times 5^{\prime} \times 10^{\prime \prime}$ \\
\hline 5 & $\begin{array}{l}\text { Tendon Duct Anchor - Rough and uneven surface - built-in } \\
\text { tendon ducts with steel strands and empty or partially grouted } \\
\text { ducts }\end{array}$ & $6.5^{\prime} \times 5^{\prime} \times 88^{\prime \prime}$ \\
\hline 6 & $\begin{array}{l}\text { Tendon Duct Anchor - Rough and uneven surface - built-in } \\
\text { tendon ducts with steel strands and empty or partially grouted } \\
\text { ducts }\end{array}$ & $6 / 5^{\prime} \times 5^{\prime} \times 16^{\prime \prime}$ \\
\hline 7 & $\begin{array}{l}\text { Honeycombing and Known Cracks - Two areas of pervious } \\
\text { concrete simulating honeycombing each at different depths and } \\
\text { two simulated cracks using sheets inserting into unset concrete } \\
\text { sections. }\end{array}$ & $6.5^{\prime} \times 5^{\prime} \times 10^{\prime \prime}$ \\
\hline
\end{tabular}

Table 4. FDOT and University of Florida Specimens

\subsubsection{Specimen 1 - Control Block}

Specimen 1 is the control block which serves as a reference for the measurements conducted on the other blocks. This control block shown in Figures 30 and 31 has no known imperfections, size variations, or steel reinforcement and is formed on uniform self-consolidating concrete.

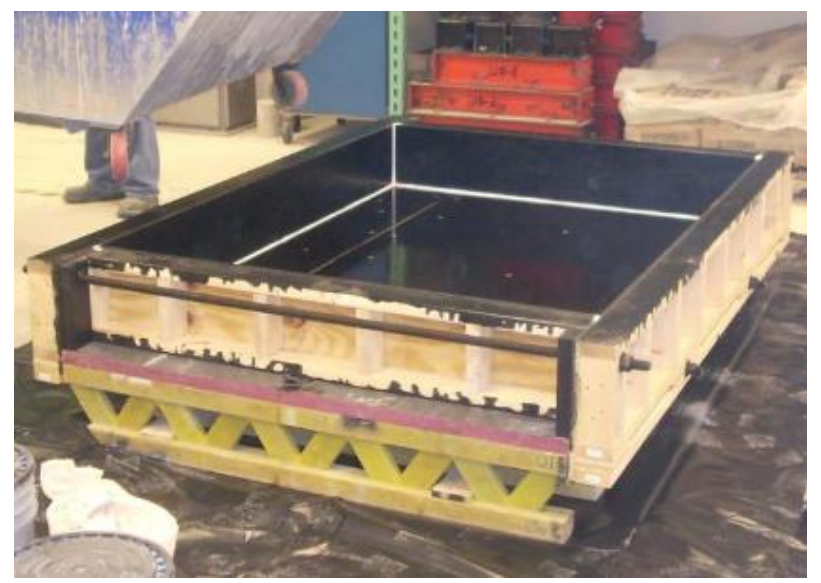

Figure 30 Form used for all standard blocks 


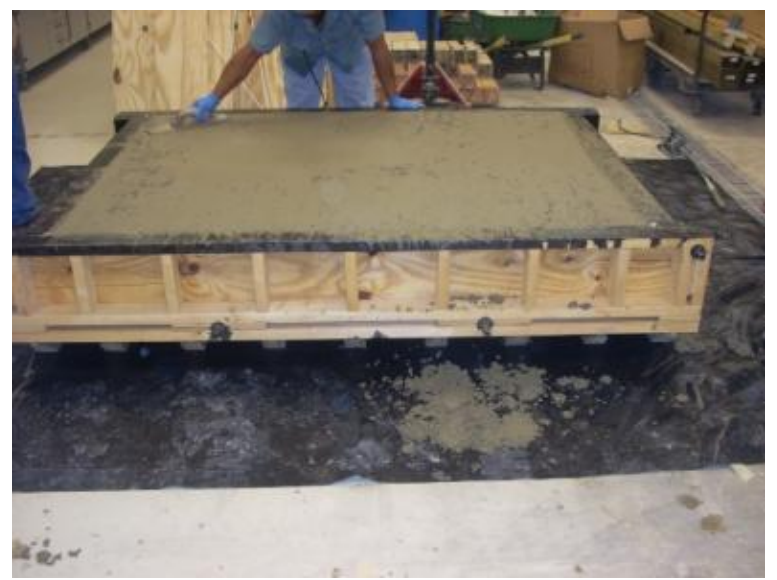

Figure 31. Control Block poured in form

\subsubsection{Specimen 2 - Steel Reinforcement}

Specimen 2 was designed to test the capabilities of NDE techniques to determine the location of steel reinforcement in relatively thin concrete slabs. To determine how the diameter of rebar effects the NDE measurements and accuracy, the size of the reinforcement bars varied from \#3 rebar to \#9 rebar in this sample. Additionally, to determine the accuracy of the measurements with respect to depth, the depth of the rebar was varied from 1 inch to 5 inches. The effect of rebar spacing on measurement accuracy can also be tested on this sample since the spacing of the rebar varies and is as close as 1.5 inches. This sample also has areas where there are one, two, or three layers of rebar at different depths.

As shown in Figure 32, the specimen has rebar placed on both the upper (front) and lower (back) sides and both parallel and perpendicular to the long axis of the specimen as well as some rebar varying in depth of placement. On the upper side (front) running perpendicular to the long axis (y), there are two sections of rebar. In one section (left hand side), the rebar size varies from \#3 to \#9 with a concrete cover of about 2.5 inches. The size of the rebar is increased to study the effect of rebar diameter on the measurements. In the second section (right hand side), the center-to-center rebar spacing varies from 1.5 inch to 10 inches to study the effects of rebar spacing on the measurements. In this section, the rebar is a standard size of \#3 and also has a concrete cover of about 2.5 inches. The second layer of rebar on the upper side (front) is parallel to the long axis of the specimen (x) and only covers $50 \%$ of the specimen to study the influence of rebar at different depths. Additionally the rebar spacing in this layer is varied from 1.4 inches to 4 inches to study the effects on localization of the second layer of rebar by spacing differences in the first layer of rebar. A diagram of the rebar layers on the upper (front) side of the block is shown in Figure 33. 


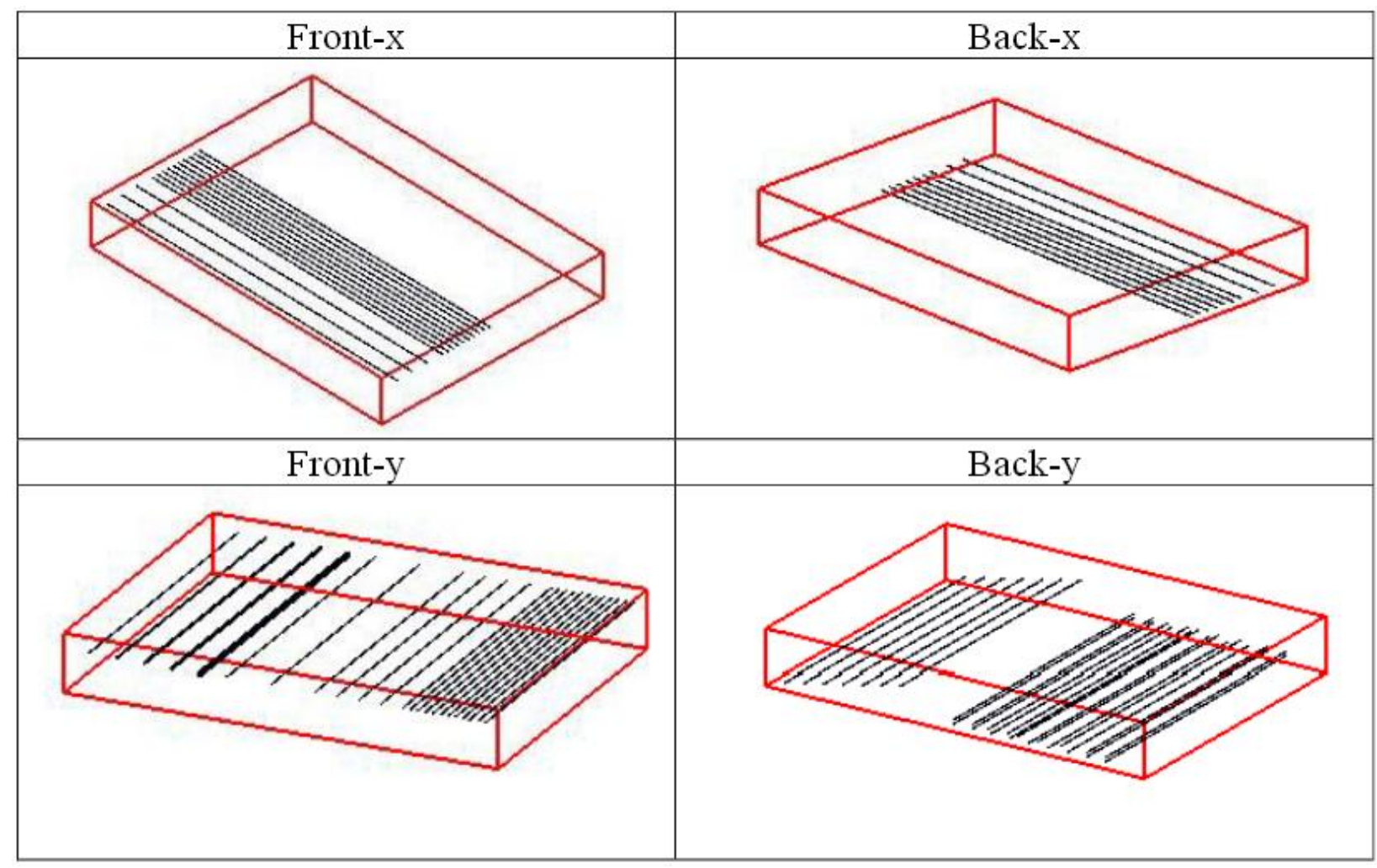

Figure 32. Layers of reinforcement in Block 2 

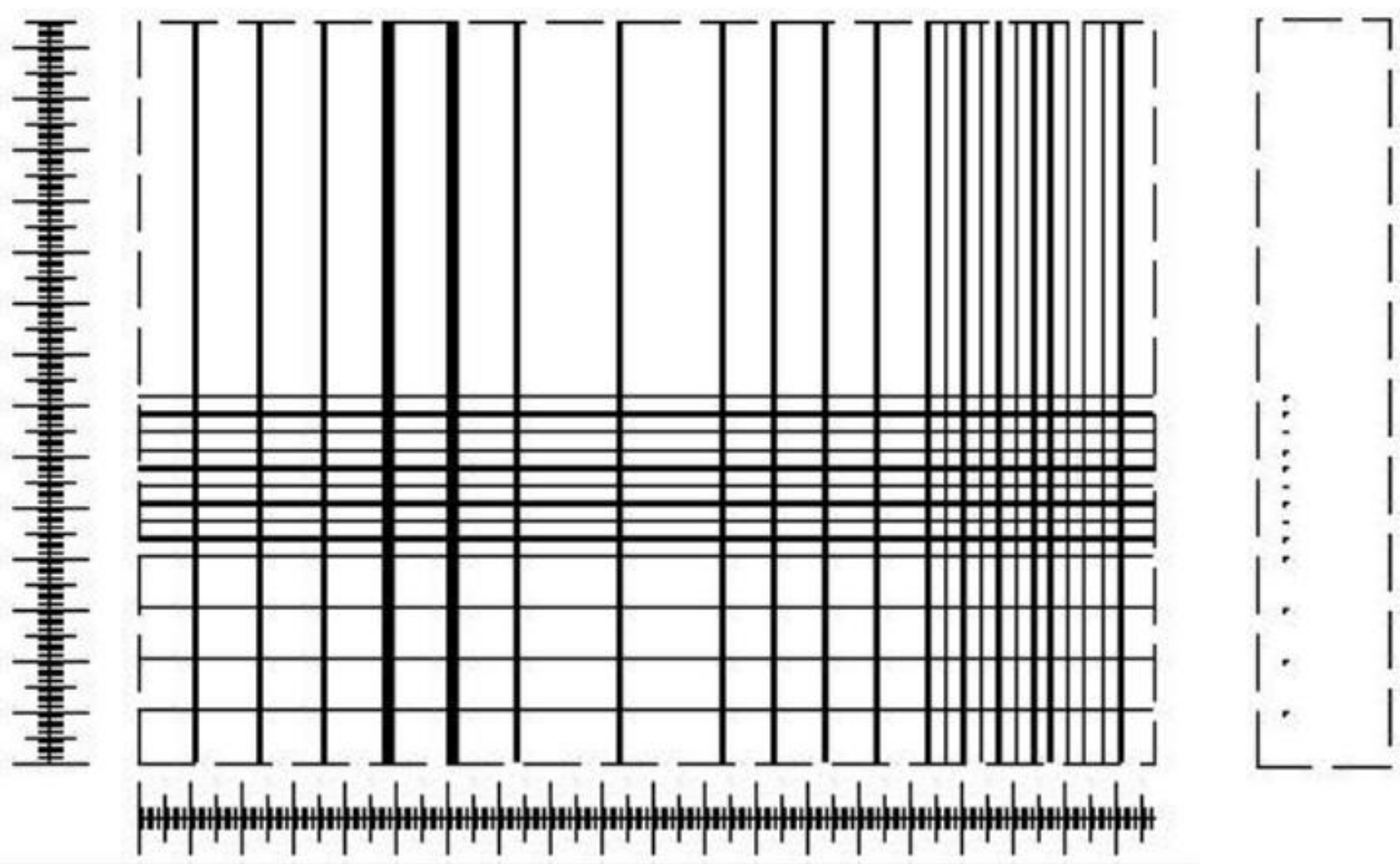

S

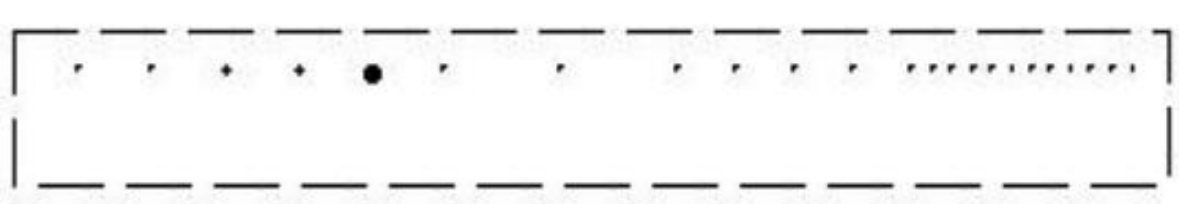

Figure 33. Steel reinforcement layers on the upper side of Block 2

As can be seen in Figure 32, on the lower side (back) running perpendicular to the long axis (y), there are again two sections of rebar. In one section (left hand side), the rebar size is held constant at a \#3 bar while the depth from the upper side (front) is decreased from 8 inches to 4 inches to investigate the depth at which rebar can be detected by the various NDE techniques. In the second section (right hand side), two identically sized rebar are stacked directly above each other while at other locations, the two identically sized rebar are stacked above each other, but offset slightly. This section allows the evaluation of the NDE in determining the rebar in the different layers and the effects of the rebar stacking or offset. A diagram of the rebar layers on the lower (back) side of the block is shown in Figure 34 . Figure 35 and 36 illustrate the fabrication of this Block 2 with steel reinforcement. 

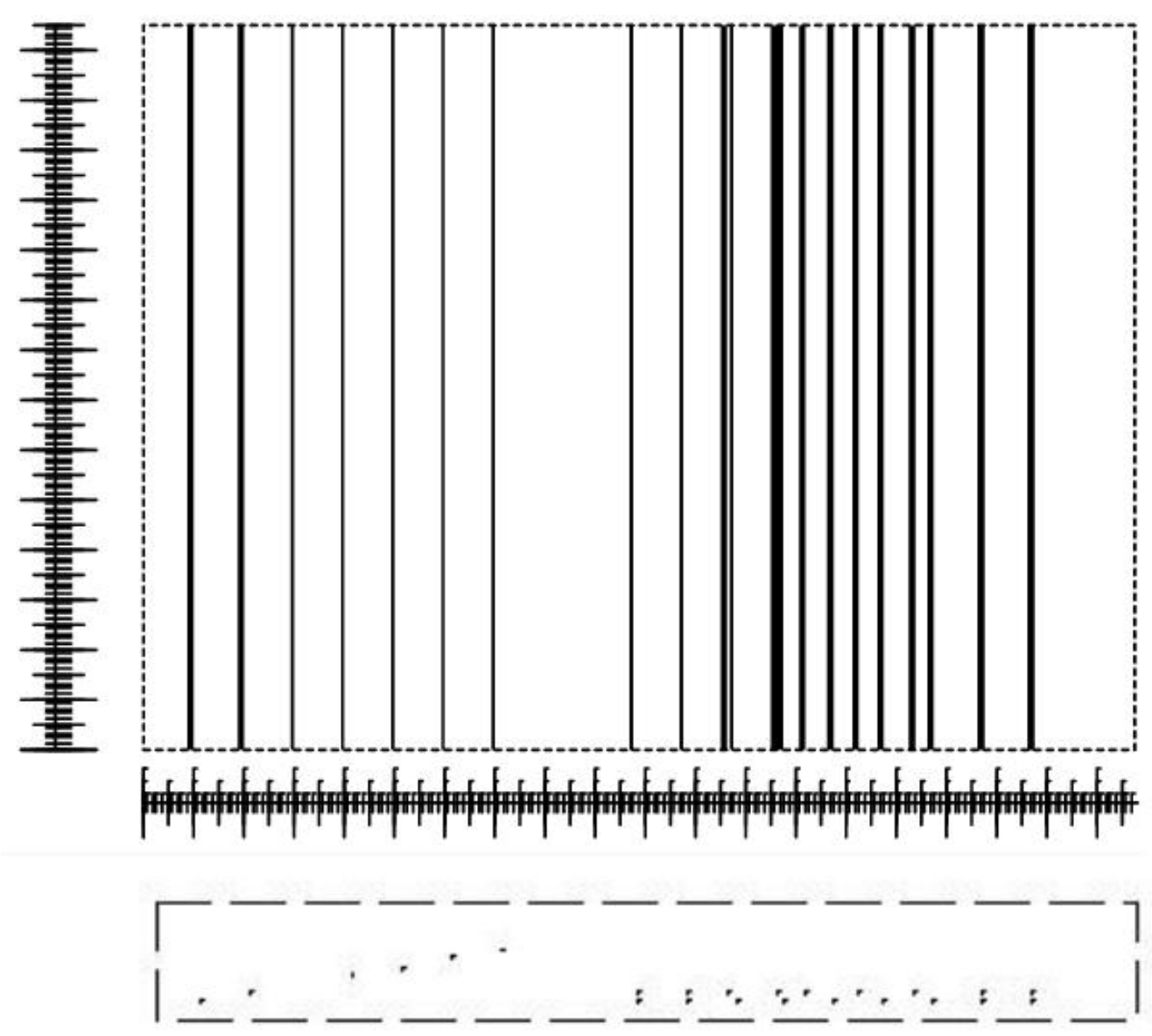

Figure 34. Steel reinforcement layers on the lower side of Block 2

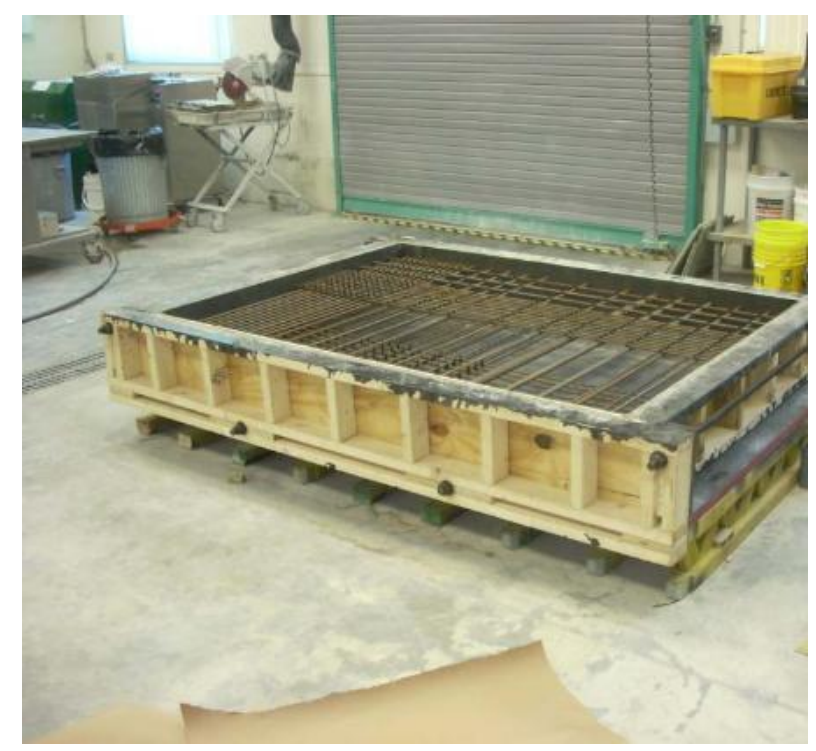

Figure 36. Consolidation of Bock 2 concrete

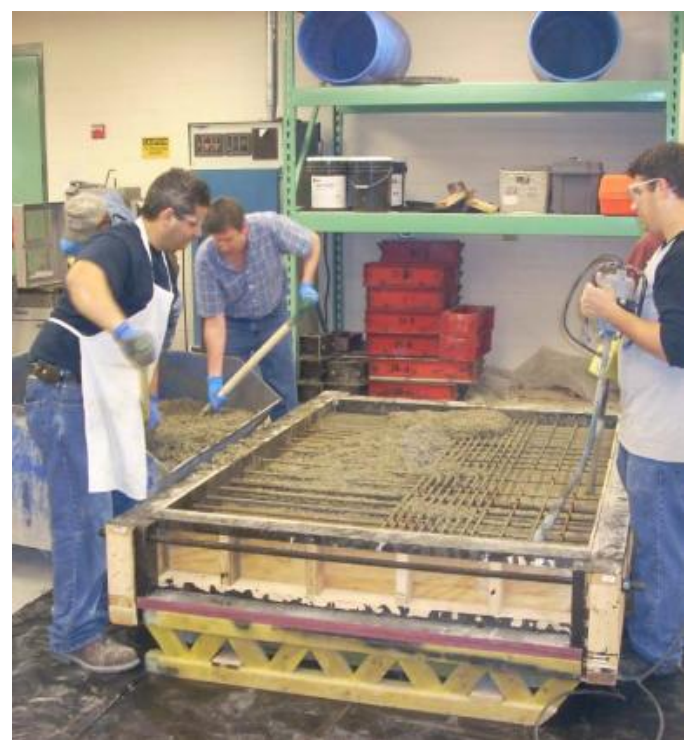

Figure 35. Formwork for Block 2 showing rebar 


\subsubsection{Specimen 3 - Varying Thicknesses}

Specimen 3 was designed to evaluate the accuracy of thickness measurements, boundary effects and the size of the area with a thickness change which is detectable by the various NDE techniques. This specimen has six identically sized areas (6.7 feet by 5 feet) with different thicknesses with one area incorporating two different sized decreased thickness areas as shown in Table 5 and Figure 37:

\begin{tabular}{|c|c|c|}
\hline Area Number & Thickness (inch) & Position \\
\hline 1 & 6.8 & Upper Left \\
\hline 2 & 14.8 & Upper Middle \\
\hline 3 & 12.8 with two differently sized reduction to 10.6 & Upper Right \\
\hline 4 & 10.8 & Lower Left \\
\hline 5 & 20.4 & Lower Middle \\
\hline 6 & 12.8 & Lower Right \\
\hline
\end{tabular}

Table 5. Thicknesses and locations in Block 3 


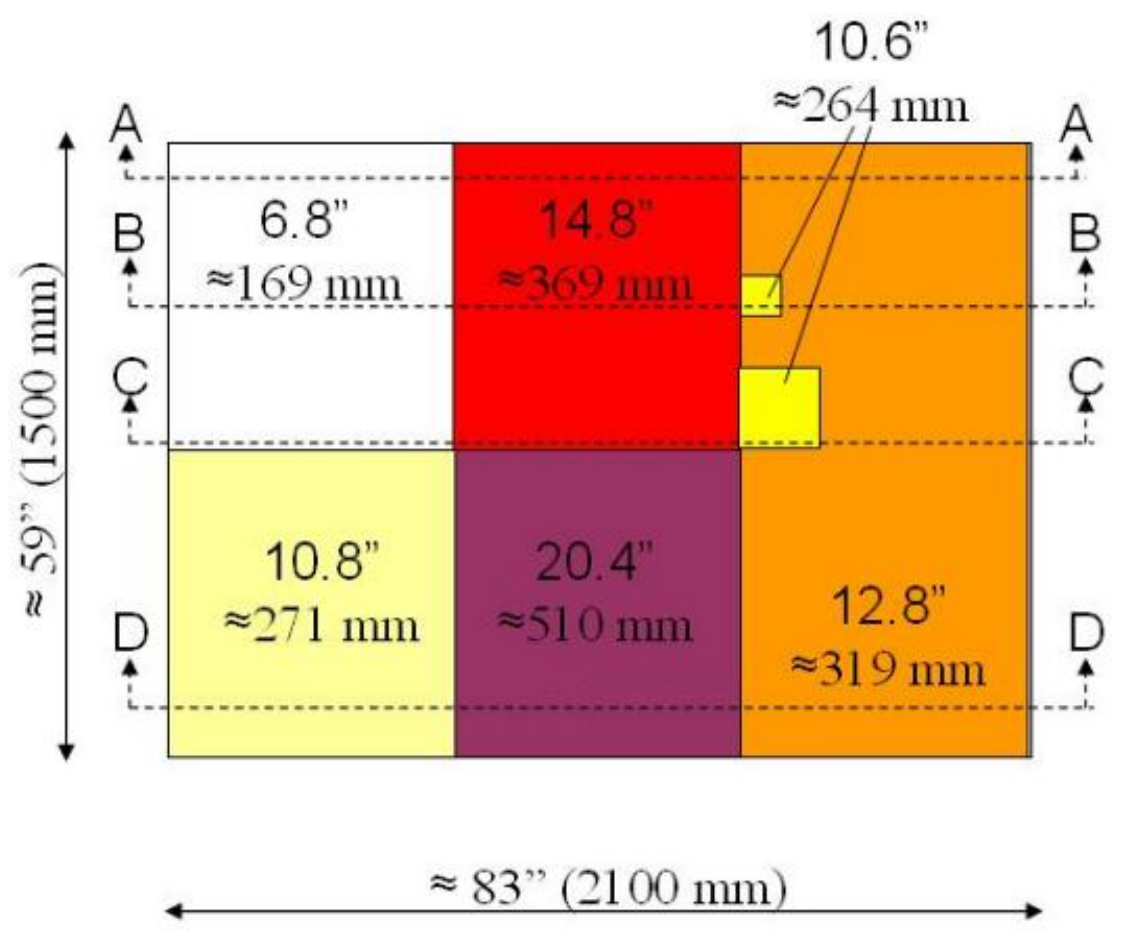

Section A-A

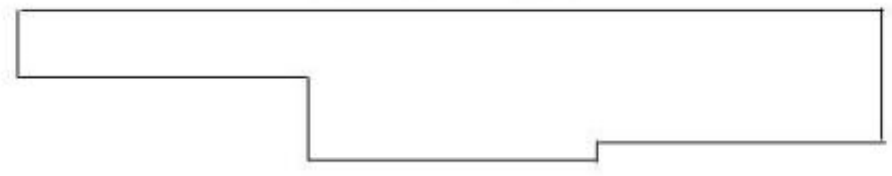

Section B-B

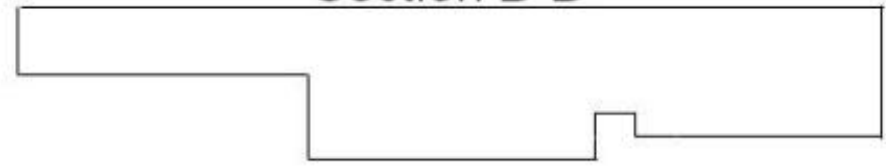

Section C-C

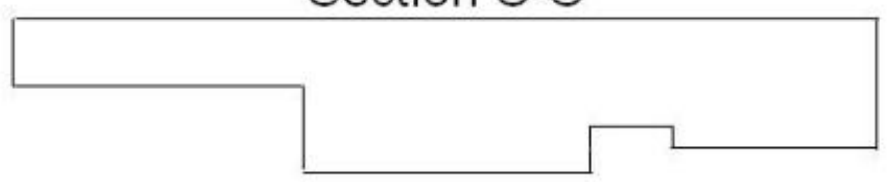

Section D-D

Figure 37. Top and sectional view of Block 3 


\subsubsection{Specimen 4 - Tendon Ducts}

Specimen 4 was designed to evaluate the ability of NDE techniques to determine several parameters associated with tendon ducts including identifying the lateral position of the duct, the depth of the duct, the dependence upon detection due to duct diameter, duct depth, duct spacing, and duct layering, and dependence upon duct material. Additionally, the ability of NDE techniques to detect and identify several aspects of the grout within the duct can be evaluated including dimensions of the void inside the duct, the location of the void within the duct, and bonding between the grout inside the duct and the duct itself. Specimen 4 was fabricated with four ducts of two different diameters ( 2 inch and 3 inch) all of which were only partially grouted. For each duct size, there is one duct located at the center of the specimen and another which is slightly off-center. To reduce the effects of specimen geometry, the ducts were placed at a slight angle and not parallel to the edges of the block as shown in Figure 38.

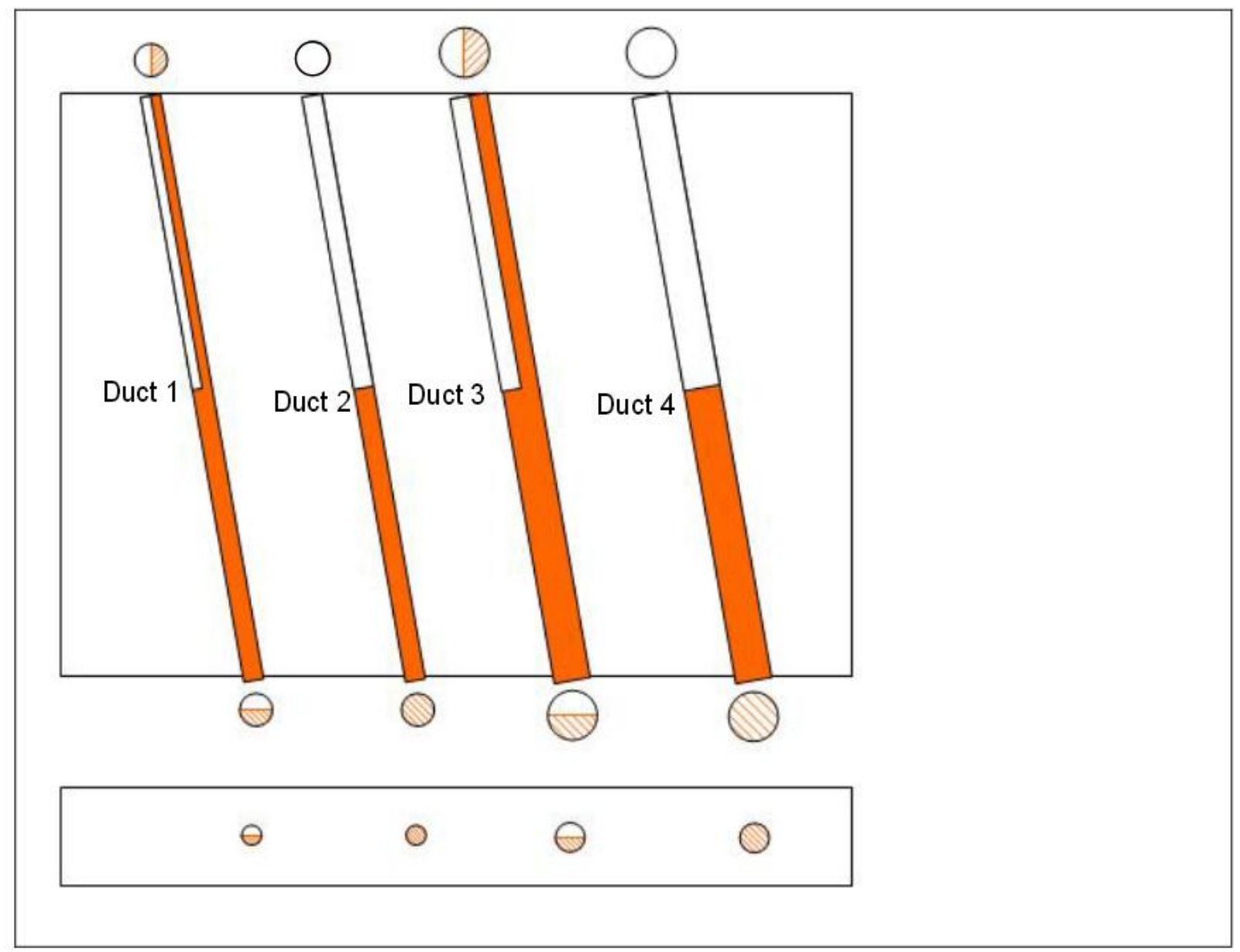

Figure 38. Four tendon ducts of two different diameters in Specimen 4

Each duct has two sections. For one duct of each size, each section is 50\% (cross section) grouted with one section having a vertical orientation of the void over half the length of the duct and the second section has a horizontal orientation over the other half length. The second duct of each size has half the length fully grouted and the other half length totally empty of grout. The complicated construction of this specimen is shown in Figures 39 through 44. 


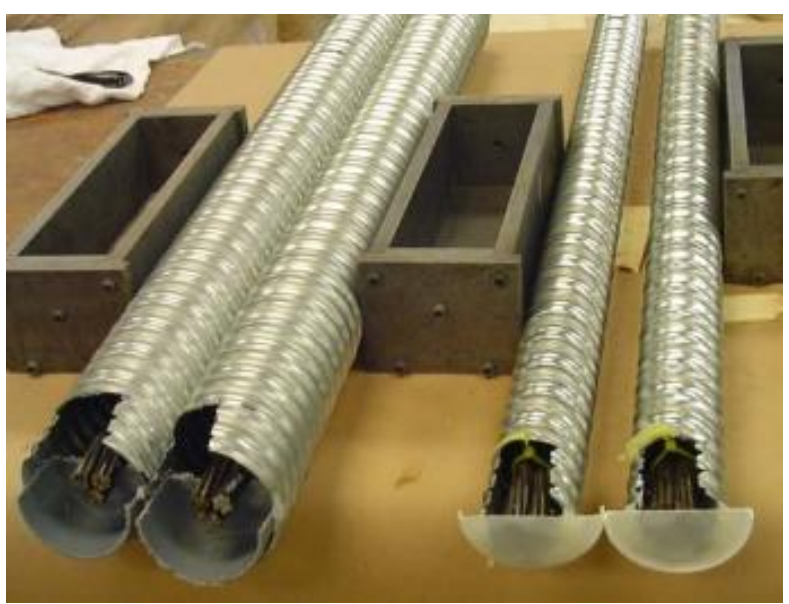

Figure 39. Preparing ducts to be partially grouted

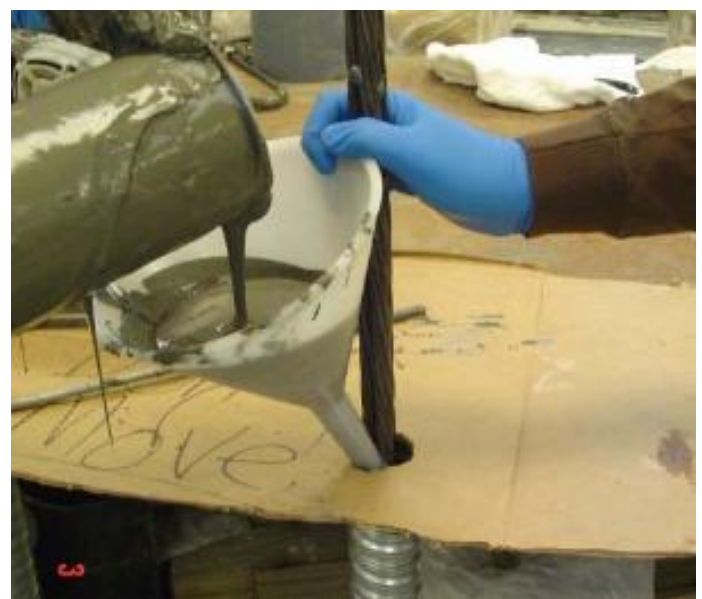

Figure 40. Filling duct portion entirely full

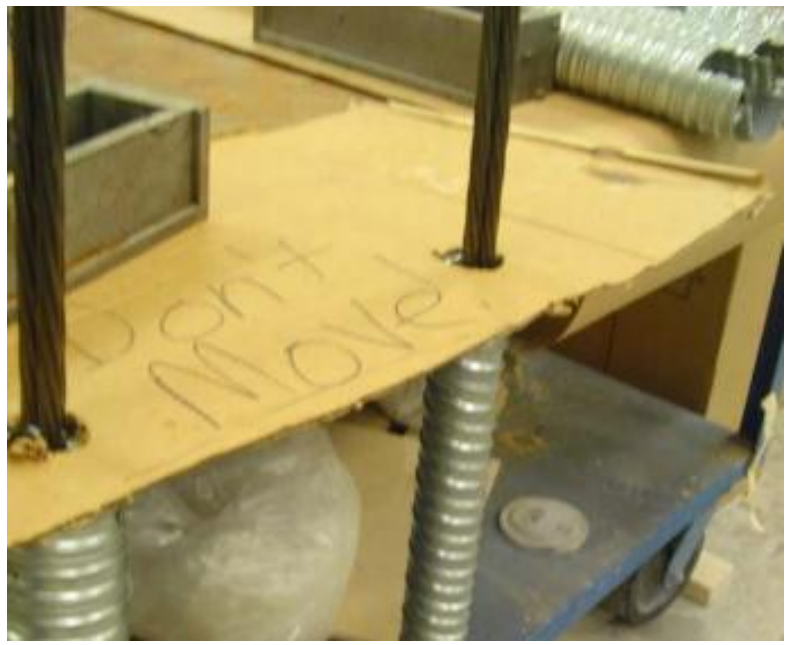

Figure 41. Fully filled duct sections curing 


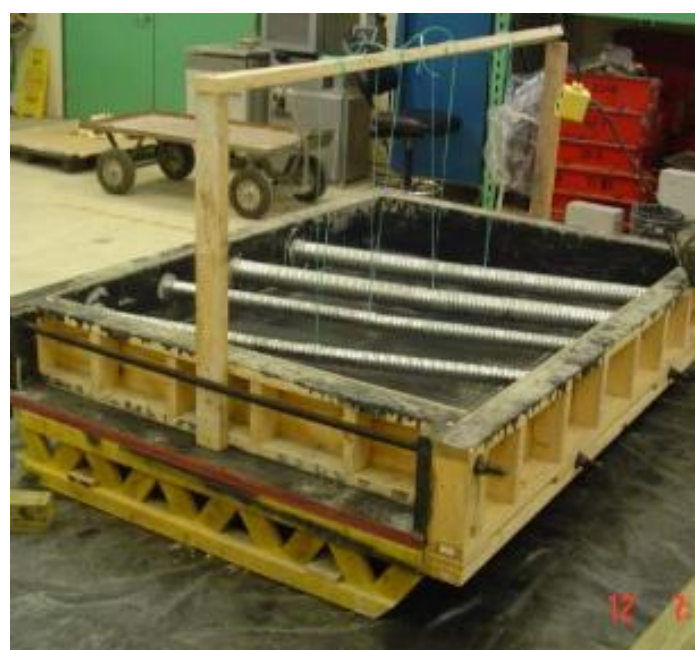

Figure 42. Ducts placed in framework

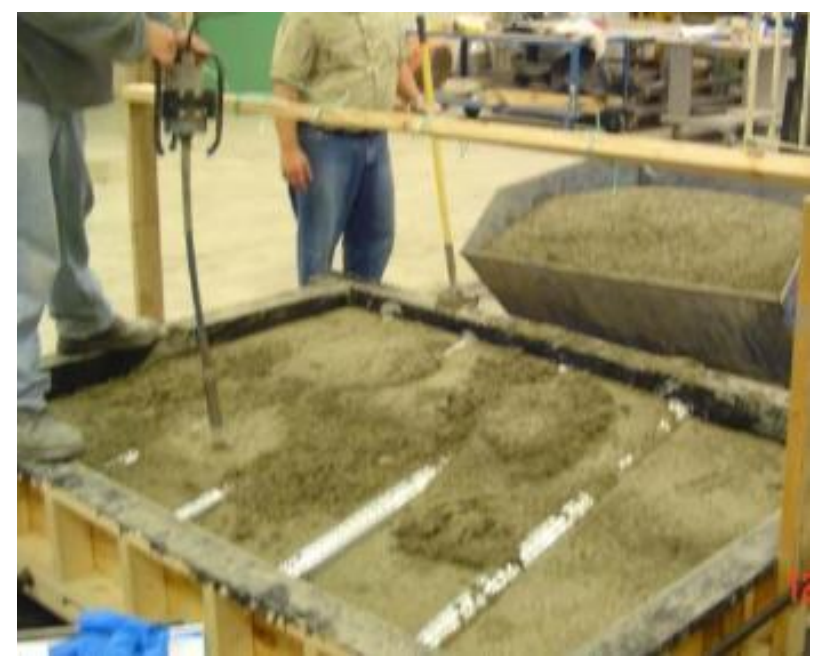

Figure 43. Pouring and compacting concrete

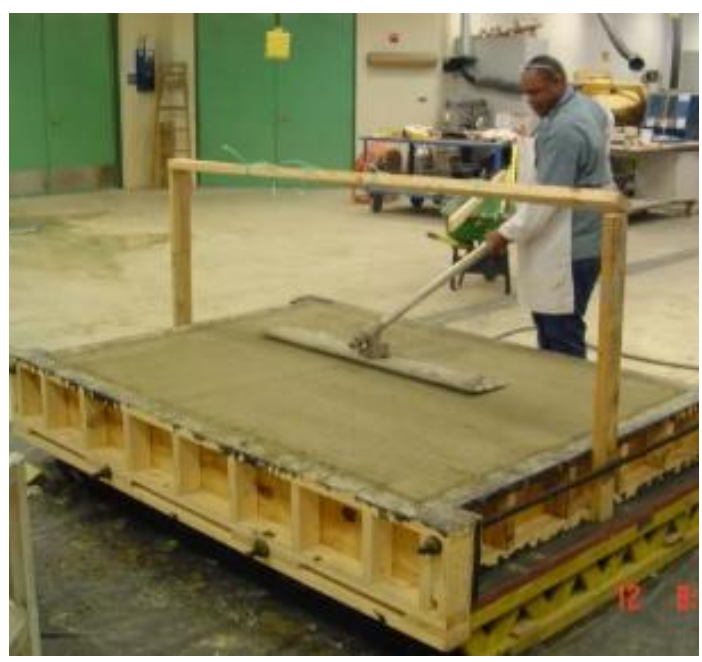

Figure 44. Finishing concrete surface 


\subsubsection{Specimen 5 - Thin Tendon Anchor Duct Section}

Specimen 5 was procured from the FDOT Structure Office in Tallahassee. It was designed to detect broken strands of tendon within a grouted duct. Specimen 5 has a base thickness of 8 inches and a tendon anchor section. Its surface is very typical exhibiting a slightly rough and uneven surface and the built-in tendon ducts have partially grouted or ungrouted tendons placed in them in known locations and covered by a mesh of rebar. Seven different types of voids within the grout can be found in the different sections of the ducts. Specimen 5 is shown in Figure 45:

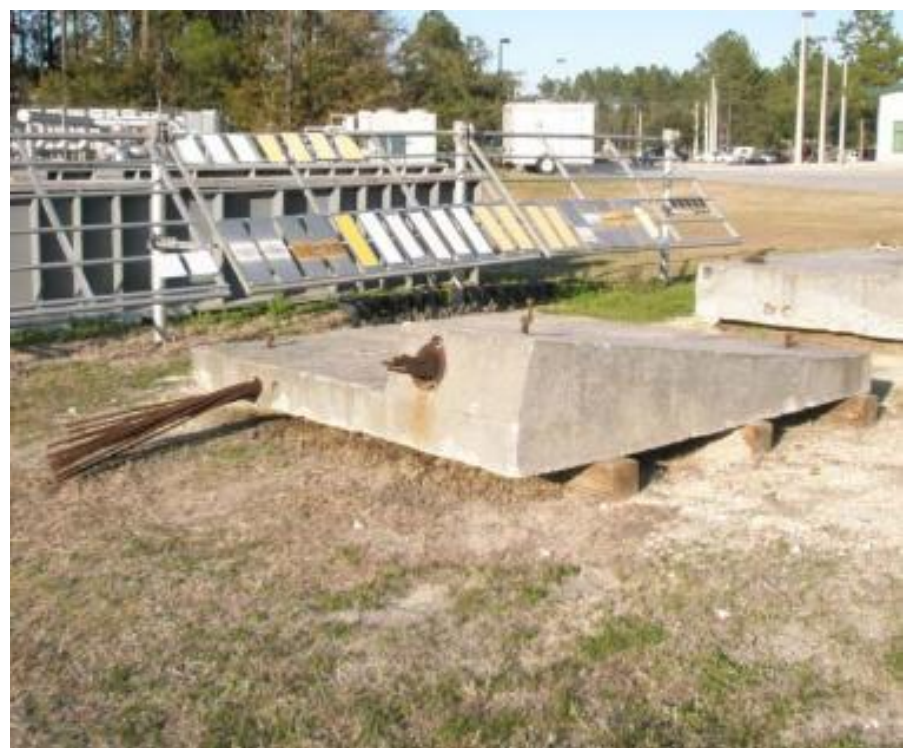

Figure 45. Specimen 5 showing thickness, anchor point, and tendons and ducts

\subsubsection{Specimen6 - Thick Tendon Anchor Duct Section}

Specimen 6 is identical to Specimen 5 except that the base thickness if 16 inches instead of 8 inches. Specimen 6 is shown in Figure 46.

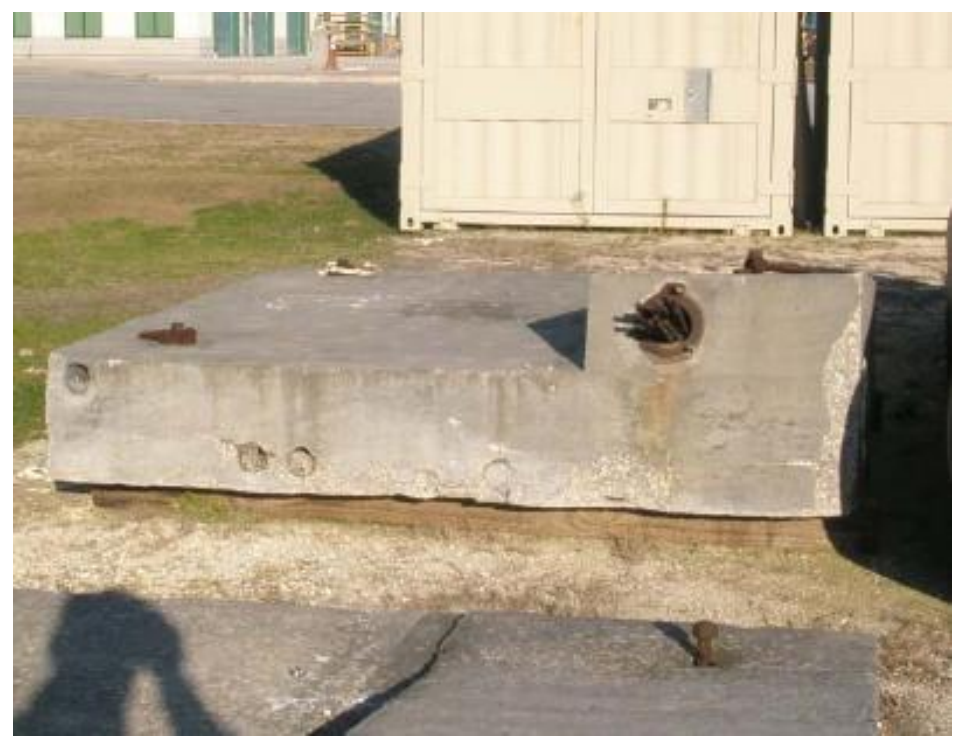

Figure 46. Specimen 6 showing thickness, anchor point, and tendons and ducts 


\subsubsection{Specimen 7 - Honeycomb and Cracking}

Specimen 7 was designed to evaluate NDE techniques relative to their ability to detect and quantify areas of honeycombing and known dimension cracking. The rectangular shaped defect areas in Specimen 7 shown in Figure 47 simulate honeycombing in concrete. Pervious concrete (no fines concrete) was used to fabricate the simulated honeycombing section which was later cast into Specimen 7 after it had cured. Likewise, after Specimen 7 was fabricated the two areas simulating known depth and size cracking were filled with wet cement and steel plates of known thickness were inserted and withdrawn during the curing of the wet cement.

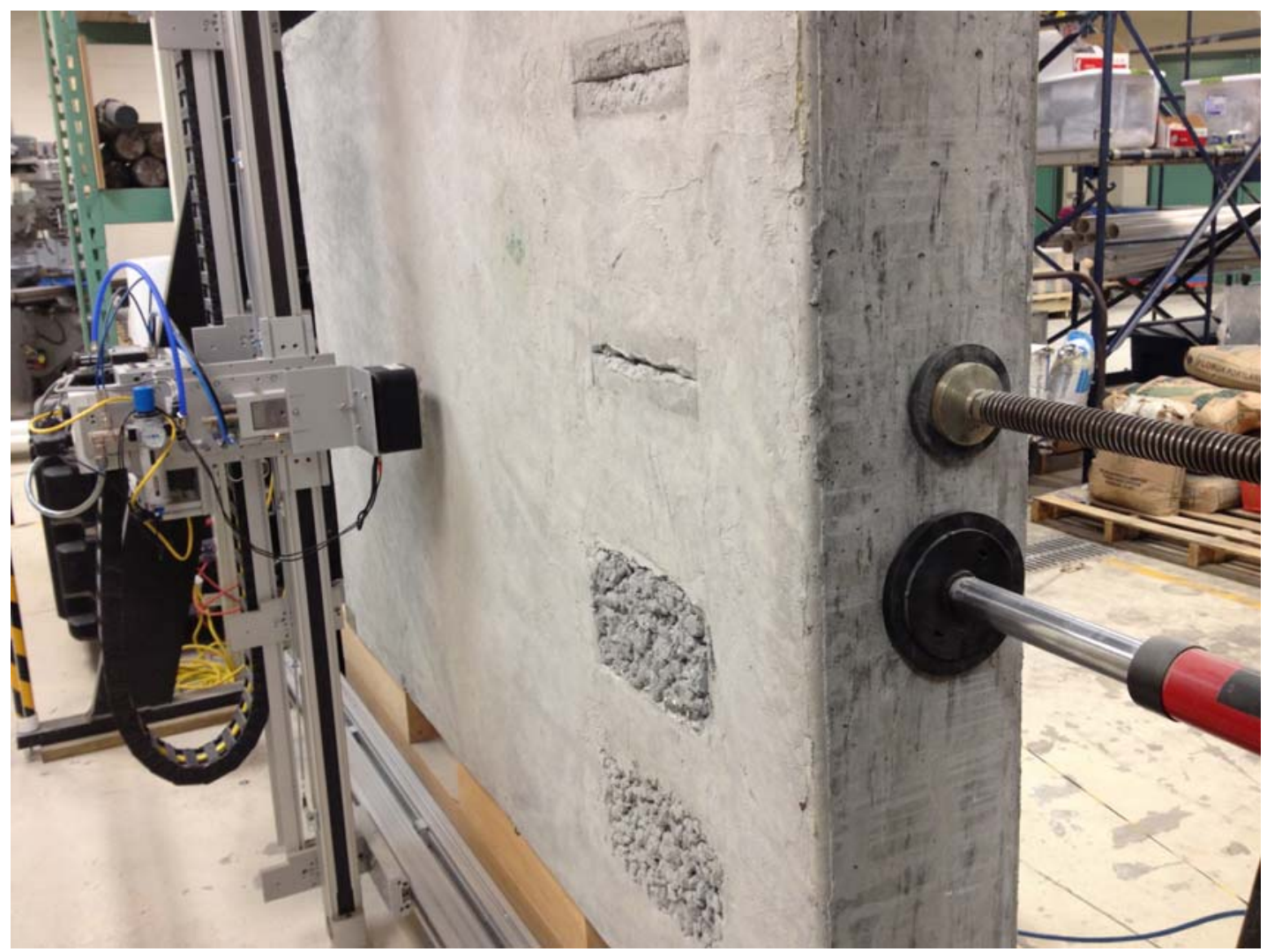

Figure 47. Honeycomb and crack areas of Specimen 7 


\section{CONCLUSIONS}

For the studies planned for this project, adequate test blocks/specimens play a key role, since they can provide defined conditions under which the different NDE concrete measurement methods can be evaluated. Material properties as well as the location of reinforcement, tendon ducts, and test flaws have to be well documented. The blocks can be field removed or artificially made. Field-removed test blocks naturally provide the most realistic simulation of the testing problem; especially those removed from NPPs with heavily reinforced steel and have been exposed to high temperature and radiation exposure. The artificial blocks can provide more defined conditions, since the critical parameters can be controlled during the block fabrication.

Test blocks need to reflect the testing problem as realistically as possible in regards to the test method applied to them. Test flaws should be as similar as possible to actual flaws in terms of how they interact with the particular test method, while at the same time the way they are generated does not necessarily have to be the same mechanism that would cause such a flaw in the field.

Artificial test blocks allow the isolation of certain testing problems as well as the variation of certain parameters. Because of the controlled conditions in the laboratory, the number of unknown variables can be decreased, which makes it possible to focus on specific aspects, investigate them in detail, and gain further information on the capabilities and limitations of the methods. However, the materials used for the fabrication of the artificial test blocks may not be representative of the original concrete fabricated some 40 to 50 years ago: old cements being usually coarser than present-day cement. Fine cements set and hydrate, generating a high heat release at the early age that can cause thermal cracking and potentially delayed ettringite formation if not cured correctly. The original admixture (plasticizer, etc.) may not be available anymore.

Furthermore, a detailed documentation and testing program must be tied to the construction of any new artificial test blocks. It should include the following.

- Detailed drawings of the position of steel elements and other inclusions

- $\quad$ Augmented monitoring including (to be defined depending on the type of degradation studied) temperature, moisture content, strain (local/structural scale), resistivity, etc.

- Thorough quality control of the placement of the embedded elements: steel reinforcement/posttensioning system, sensors and "prefabricated" flaws (voids, inclusions, plates, etc.)

- Significant material testing of concrete properties at different ages (to be defined depending on the type of degradation studied) including mechanical properties (strength, elasticity, shrinkage, etc.), durability-related properties (porosity, permeability, diffusions coefficients, etc.); additional control samples might also be required

To minimize artifacts caused by boundary effects, the dimensions of the specimens should not be too compact. The exact size will depend on the NDE method used. The minimum dimensions of the test sample are directly related to the thickness of the sample. The first reflected wave received is normally assumed to be from the rear surface. If the ultrasonic wave is modeled as a spherical propagation from the point source then the distance from the source location to the rear surface must be the minimum dimension.

The concrete sample specimens at the Federal Highway Administration NDE Validation Center at the Turner-Fairbank Highway Research Center, and the Florida Department of Transportation NDE Validation Facility in conjunction with the Department of Civil and Coastal Engineering Department University of Florida, Gainesville are usable for concrete NDE evaluations, however, none of them, 
especially the specially constructed ones detailed in this report, are of the cross sectional thickness or have the amount of steel reinforcing which is typical of a commercial nuclear power plant structures.

The High Flux Isotope Reactor (HFIR) is located at ORNL and possesses thick, heavily reinforced concrete structure although they are not as extensive as those of commercial nuclear power plants. The concrete in these HFIR structures has also been irradiated which would make them more typical of some concrete structures at commercial nuclear power plants. Some of these concrete structures at HFIR could be make available for NDE research.

Additionally, there are several commercial nuclear power plants undergoing the decommissioning process and it would be ideal to secure concrete sections of these plants for use in testing NDE techniques.

However, the cost for obtaining, transportation, and storage of these samples is high. To obtain samples large enough to eliminate boundary effects in NDE evaluations, their weigh would be prohibitive for most methods of shipping (3' x 9' x 9' section is about the largest which could be shipped using typical trucks over highways).

The effects of long term irradiation at commercial nuclear power plant levels on concrete are yet to be determined. Therefore, the importance of obtaining specimens with an irradiation history is still to be determined. However, there is a need to obtain concrete specimens with the appropriate cross sectional thickness and steel reinforcement.

It is the recommendation of this report that at least one concrete test sample representative of the cross section of a commercial nuclear power reactor be fabricated for concrete NDE evaluations. Additionally, the HFIR reactor should be utilized for concrete NDE research and evaluation and an effort should be made to obtain or have access to concrete specimens from decommissioned commercial nuclear power plants. 


\section{REFERENCES}

1. Clayton and Hileman, "Light Water Reactor Sustainability (LWRS) Non-Destructive Evaluation (NDE) for concrete Research and Development (R\&D) Roadmap” ORNL/TM2012/360, September 2012

2. "Non-Destructive Inspection Protocol for Reinforced Concrete Highway Barriers and Bridge Railings” Federal Highway Administration NDE Validation Center, McLean, VA, 2013

3. Hiltunen, Algernon, and Ferraro, "Validation of Nondestructive Testing Equipment for Concrete - Final Report”, Florida Department of Transportation Research Center and University of Florida Department of Civil and Coastal Engineering, Gainesville, July 2011 